\title{
Measurement of heat flux distribution of supercritical kerosene fueled supersonic combustor
}

\author{
Di Cheng ${ }^{1}$, Jing Wang ${ }^{2}$, Jian Gong ${ }^{3}$, Yang $\mathrm{Lu}^{4}$, Wei Yao ${ }^{5}$, Long Li ${ }^{6}$, Xuejun Fan ${ }^{7}$ \\ 1,3 Research and Development Center, China Academy of Aerospace Aerodynamics, Fengtai, Beijing, \\ 100074, P.R.China
}

2,4,5,6,7 State Key Laboratory of High Temperature Gas Dynamics, Institute of Mechanics, Chinese Academy of Sciences, Haidian, Beijing, 100190, P.R.China

\begin{abstract}
Heat flux distribution of supercritical kerosene fueled, single-side expanded supersonic combustor with two dislocated cavities was experimentally studied. The effects of inlet Mach number, total temperature, mass flow rate and fuel equivalence ratio on the combustion and heat transfer characteristics in the supersonic combustor were analyzed. The isolator inlet Mach number is 2.0 and 2.5, the total temperature is $1305 \mathrm{~K}$ to $1701 \mathrm{~K}$ and the mass flow rate is $2.0 \mathrm{~kg} / \mathrm{s}$ to $3.0 \mathrm{~kg} / \mathrm{s}$. Pilot hydrogen and liquid or supercritical $(773 \pm 20 \mathrm{~K})$ China No.3 kerosene were injected in front of the cavities with the equivalence ratio ranges from 0.52 to 0.88 . Results show that heat flux increases with the inlet temperature and mass flow rate, however, the influence of equivalence ratio is non-monotonic in the range of this study. The two inlet Mach numbers also trigger different combustion modes, which further complicates the heat flux distribution. In the end, a three parameter correlation is proposed and fitted to normalize the experiment results for comparison and discussion.
\end{abstract}

Keyword: Heat flux distribution, supersonic combustion, supercritical kerosene, scramjet

\section{Nomenclature}

$\dot{q}=$ Heat flux

$q_{m}=$ Mass flow

$\phi \quad=$ Equivalence ratio

$K_{1}, K_{2}=$ Sensitivity of heat flux and temperature difference of the heat flux sensor

$S t=$ Stanton number

$R e=$ Reynolds number

$\mathrm{Pr}=$ Prandtl number

$M a=$ Isolator inlet Mach number

$E=$ Output signal of heat flux sensor

$T_{b}=$ Body temperature of heat flux sensor

\footnotetext{
${ }^{1}$ Engineer, chengdi123000@gmail.com

2 Associate Professor, wangjing@imech.ac.cn, Member AIAA

3 Senior Engineer, 13641010905@139.com

${ }^{4}$ Assistant Professor, luyang@imech.ac.cn, Member AIAA

5 Associate Professor, weiyao@imech.ac.cn, Member AIAA

${ }^{6}$ Assistant Professor, 11i918@163.com, Member AIAA

${ }^{7}$ Professor, Corresponding author, xfan@imech.ac.cn, Phone +86-10-82544052, No. 15 Beisihuanxi Road, Beijing, China. Member AIAA
} 


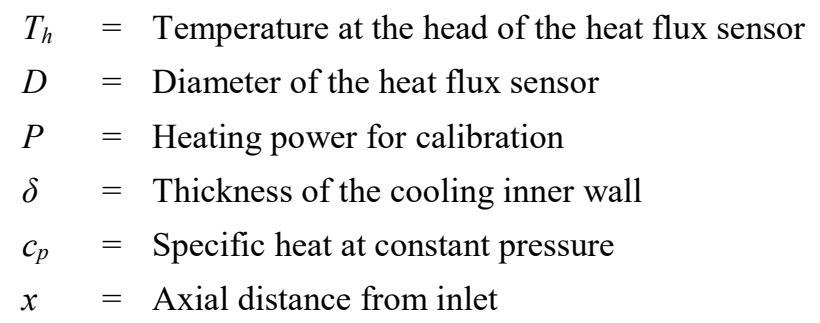

\title{
Subscript
}

$0=$ Stagnation condition

\author{
Superscript \\ * $\quad=$ Reference state of Eckert's Reference Enthalpy Method
}

\section{Introduction}

Measurement of heat flux distribution is critical to the development of thermal protection system for supersonic combustor. At flight Mach number about 6-8, the total temperature of gas after combustion may exceed $2800 \mathrm{~K}$ and the average wall heat flux to the combustor inner wall ranges from 1.0 to beyond 10.0 $\mathrm{MW} / \mathrm{m}^{2}$ depending on the combustor design and the flight condition [1]. In order to deal with the challenge of combustor cooling and improve fuel mixing and combustion efficiency, liquid kerosene is heated to a supercritical state or even cracked gas by convective heat transfer along the cooling channels in the combustor walls before reaching the fuel injector [2]. The heat flux distribution might be changed with supercritical kerosene. Besides, heat flux distribution is an important indicator of flow field and heat release in the combustor, which could promote the understanding of supersonic combustion as well.

However, limited amount of previous studies involves direct measurements of heat flux distribution due to three technological difficulties to obtain faithful results. First, the high speed corrosive flow in supersonic combustor is harsh to the survival and normal working of heat flux sensors attached to the wall. Second, the heat flux varies with wall temperature in convective environment as $\dot{q}=h\left(T_{a w}-T_{w}\right)$, so the wall temperature $T_{w}$ is needed to interpret the heat flux measurement $\dot{q}$, but simultaneous measurement of wall temperature and heat flux is difficult especially for ignited combustor in thermal equilibrium. Third, the size of supersonic combustor and the work duration of its test facility limit the choice of sensors [3].

In previous studies, Morgan .et.al. shows that the measured heat flux of a model supersonic combustor lies between values predicted by laminar and turbulence theory[4], but it is difficult to identify the transition regions. Traci et.al. summarized some heat flux distribution measurement data in their report of VITMAC heat analysis software package[5]. The Direct-Connect Combustor (DCC) experiment data were obtained from 8 calorimeters for $\mathrm{Ma}=6, \phi_{H 2}=0.37$ and $\mathrm{Ma}=6, \phi_{H 2}=0.52$ flight condition, and the results show that heat flux increase with $\phi_{\mathrm{H} 2}$, and the heat flux at inlet rises due to the back pressure caused by combustion [5]. But only one wall is measured in the asymmetric combustor, the heat flux on the wall without combustion is unmeasured. Then the side-to-side variation of heat flux is measured in Direct-Connect Arc Facility (DCAF) experiment of Mach 10 and 12 flight condition [5], which used inner and outer thermocouples at 18 points to capture the heat flux of two opposite walls. According to the result, the influence of flow stratification is ineligible for scramjet, which is also confirmed in the work of Stouffer et.al. [6]. In the work of Stouffer et.al., heat flux is measured by 84 co-axial thermocouples with two different fuels (ethylene fueled and reformed Jet-A) at Mach 5.6 flight condition, but the equivalence ratio is not given in the published report[6]. Ueda et.al. investigated the hydrogen fueled side-wall compression scramjet combustor with different fuel injection schemes at one Mach 6 flight condition with 6 Gardon type heat flux sensor [7]. 
The results show that the heat flux decreased if fuel is injected in the opposite wall, a CFD result was given but only order of magnitude could be matched. Paul et.al. used 4 direct-write heat flux sensors to ethylene fueled combustor at flight Mach 5 at different equivalence ratio and dynamic pressure, the result confirms that heat flux increase with dynamic pressure and equivalence ratio but the spatial resolution is too low[8] [9]. With the capability of High Enthalpy Shock Tunnel Göttingen, Gardner et.al. and Jan Martinez et.al. used coaxial thermocouple to measure the HyShot and HyShot II combustor in flight condition of about Mach 7.6 at about $30 \mathrm{~km}[10,11]$. Comparing with CFD result, the absolute value of heat flux is sensitive to turbulence model and combustion model. In the recent work of Li et.al., 6 Gardon type heat flux sensors were used to measure the heat flux of fuel injection wall of a liquid kerosene fueled 2D-type combustor, and the heat flux variations with different inflow total temperature, mass flow rate and equivalence ratio were studied with Mach 2.5 inflow[12]. The result shows similar trend as previous studies but does not match with quasi-1d flow calculation in combustion region due to flow stratification.

To sum up, heat flux distribution could be influenced by many factors, such as combustor geometry, fuel type, equivalence ratio, turbulence, inlet condition, pre-combustion shock train, flow stratification etc. The experimental study on heat flux distribution in supersonic combustor is still insufficient in spatial resolution, circumferential distribution and parametric study. And because of the complexity in the phenomena, it is also noted that usually only orders of magnitude can be matched between experimental, empirical and numerical results in combustion region [4, 5, 7]. Comprehensive and parametric study of the important influencing factors of heat flux distribution for supersonic combustors is still desirable.

In order to measure heat flux, heat flux sensors are needed. Working principles of heat flux sensors used in aforementioned studies can be divided into two categories: transient method and steady method [5]. A typical transient sensor, such as coaxial thermocouple or copper block type calorimeter, consists of a temperature sensor and a heat sink [6]. Temporal data of the temperature during the test were recorded and a transient heat conduction equation was solved to convert the temperature history to heat flux. This kind of method could work on uncooled small scale model combustor with short duration facility and gives temperature and heat flux simultaneously. However, the presumed form of heat transfer equation and boundary conditions are skeptical in long duration experiment and real combustor geometry [3]. The survivability of uncooled model also limits the highest inner wall temperature and running time of experiment, which makes it difficult to measure ignited combustor in thermal equilibrium with combustor walls. Steady method is another approach used by many researchers $[3,5,7,11]$. Typical steady heat flux sensors include calorimeter, Gardon gauge based sensor and thermopile type sensors etc. Usually steady heat flux sensors are larger in size than transient sensors, and the size effect and cooling effect on thermal boundary layer and model structure are also greater. But the environment insensitivity, endurance and ease of calibration of steady sensor ensure better repeatability and accuracy. Another drawback of steady sensors is that the response time of cooled steady sensor is usually a few orders of magnitude larger than transient sensor, which means it is unable to capture heat flux fluctuation and thus cannot be used with short duration facilities. In this paper, in order to measure the average heat flux of an ignited supersonic combustor on a long duration direct-connect facility, in-house made water cooled Gardon type heat flux sensors were calibrated and used.

In this paper heat flux distribution in supersonic combustor is experimentally studied, a special 2D water-cooled and kerosene-fueled scramjet combustor was designed and tested. Twenty calibrated heat flux sensors were used to measure the heat flux distribution on three combustor walls under different mass flow rates, total temperatures, inlet Mach numbers, equivalence ratios and fuel temperature, with the results analyzed and discussed. 


\section{Experimental Setup and Operation}

\subsection{Long Duration Direct-Connect Supersonic Combustion Test Facility}

Tests were conducted on a Long Duration Direct-Connect Supersonic Combustion Test Facility (abbreviated as DTZ in the following) located in State Key Laboratory of High Temperature Gas Dynamics. The DTZ shown in Figure 1 consists of an air supply system, an air heater, a nozzle section, a combustor assembly, a water-cooling system, a data acquisition and control system and a fuel heating and delivery system. Pressure and heat flux measurement systems are attached to the combustor assembly and communicated via the data acquisition and control system.

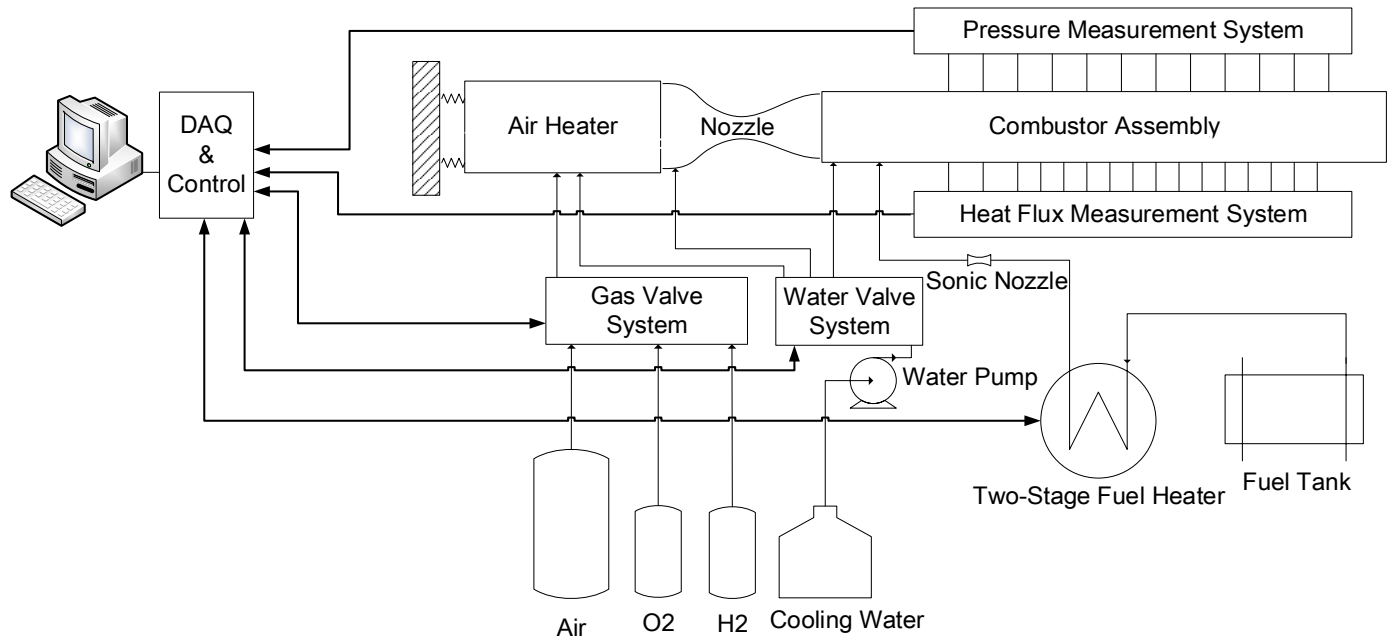

Figure 1 Schematic diagram of the test facility.

The vitiated air, which is supplied by burning $\mathrm{H}_{2}$ in air with oxygen replenishment, has a raised stagnation temperature of $700-2200 \mathrm{~K}$ and a stagnation pressure of $0.6-4.0 \mathrm{MPa}$. The stagnation pressure and temperature of the vitiated airflow are measured by using a CYB-10S pressure transducer and a Type-B thermocouple, respectively. The mass flow rate of the gas flows (air, hydrogen and oxygen) are controlled and measured by sonic nozzles. The mass flow rate coefficients of the sonic nozzles were calibrated with an uncertainty less than $1 \%$. The shells of the air heater and other aerodynamic heating parts are cooled by water. The total vitiated air mass flow rate is up to $5 \mathrm{~kg} / \mathrm{s}$, and the running time is up to $60 \mathrm{~s}$.

\subsection{Combustor Assembly}

Schematic drawing of the combustor assembly is shown in Figure 2, where the cross section of isolator inlet is $70 \mathrm{~mm} \times 150 \mathrm{~mm}$. The combustor assembly consists of three sections made of stainless steel SUS321, i.e. isolator, combustor and expander, which are single-side expanded with $0.7^{\circ}, 2.0^{\circ}$ and $5.3^{\circ}$ respectively. Two dislocated cavities are placed on the upper wall and the lower wall of the combustor respectively. The combustor assembly is cooled by water. The inner wall thickness is $2 \mathrm{~mm}$ embed with water cooling channels of $3 \times 3 \mathrm{~mm}^{2}$ cross section at intervals of $5 \mathrm{~mm}$. The total wall thickness is $20 \mathrm{~mm}$ and the inner wall surface roughness is $R a=3.2$. The spatial details of cavity modules are shown in Figure 2. Each of the modules has a step of $12 \mathrm{~mm}$ in depth, an aft ramp of $50^{\circ}$ and an overall length-and-depth ratio of 7 . The pilot $\mathrm{H}_{2}$ is injected from $4 \times \phi 2.65$ evenly spaced holes $64 \mathrm{~mm}$ ahead of cavity, liquid kerosene was injected from $9 \times \phi 0.4$ evenly spaced holes, and supercritical kerosene is injected from $9 \times \phi 1$ evenly spaced holes located $8 \mathrm{~mm}$ ahead of the cavity. 


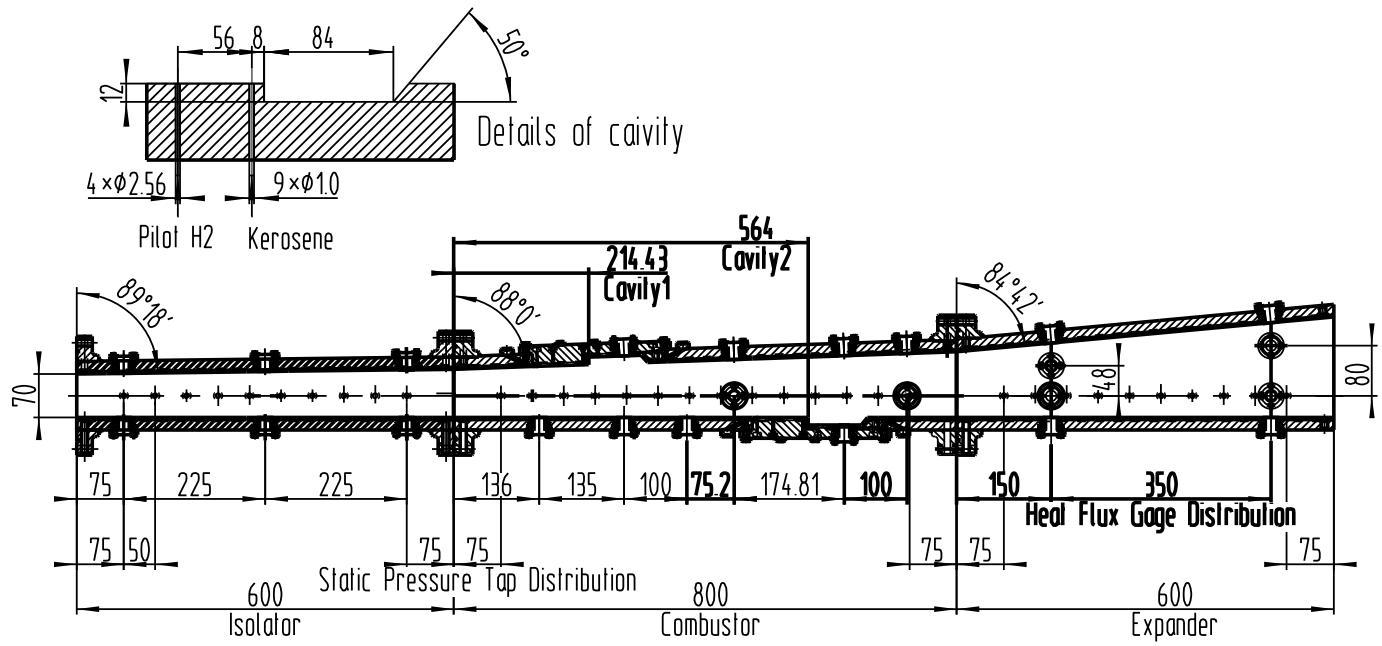

Figure 2 Drawing of the combustor assembly, unit in $\mathbf{~ m m}$.

\subsection{Fuel delivery and heating system}

In the test cases, the pilot hydrogen and China No. 3 kerosene for combustion are injected at locations before the two cavities. Hydrogen is directly injected from gas bottles via pressure regulator and sonic nozzle. Liquid kerosene is injected at room temperature via a piston pump driven by ABB frequency converter. The supercritical kerosene is supplied by a two-stage fuel heating system as Figure 3. The supercritical kerosene is injected at $768 \pm 5 \mathrm{~K}$ and the injection pressure is adjusted from 2.87 to $4.56 \mathrm{MPa}$ to control the mass flow rate. The kerosene mass rate ratio injected at the upstream and downstream locations is 1 , which is controlled by sonic nozzles with the same diameter. Details of the fuel heating system can be found in literature [13].

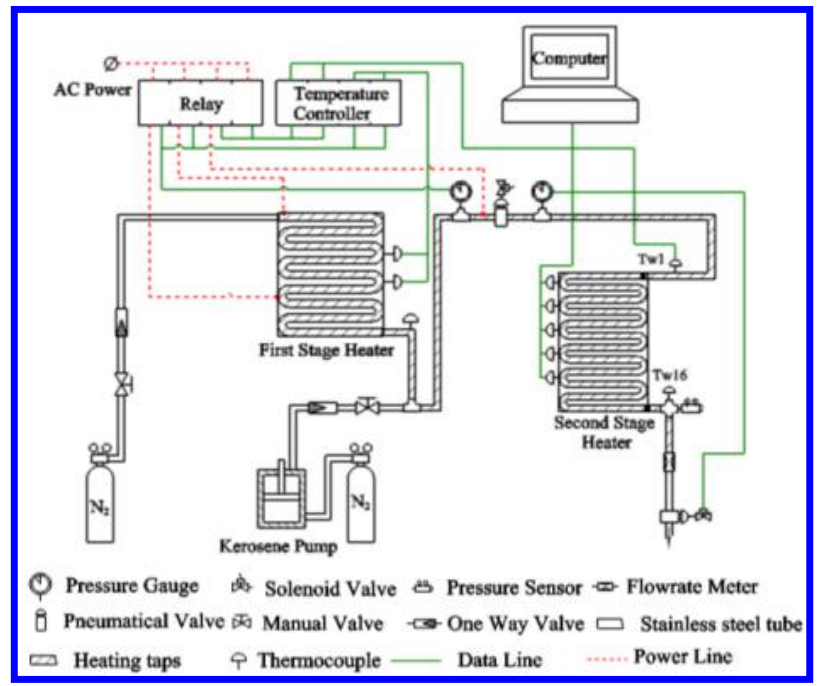

Figure 3 Schematic of kerosene delivery and heating system. (Courtesy of Dr. Taichang Zhang)

\subsection{Static pressure and heat flux measurement system}

The static pressure measurement locations are drilled on the east wall of the combustor assembly, as shown in Figure 2. Static pressure is measured by Motorola MPX2200 pressure transducers along the east side of the combustor assembly with $50 \mathrm{~mm}$ interval except in the periphery of the flanges. The experimental uncertainty of the static pressure measurement is about $0.1 \%$. Conditioned signals are collected by data acquisition system of DTZ.

Twenty-four installation locations for heat flux sensors were machined on the upper, lower and west side walls of the combustor assembly as shown in Figure 2. The sensors on the upper and lower walls are 
located in the centerline. As shown in Figure 4, the heat flux measurement system consists of a cooling water subsystem, sensors and a data acquisition subsystem.

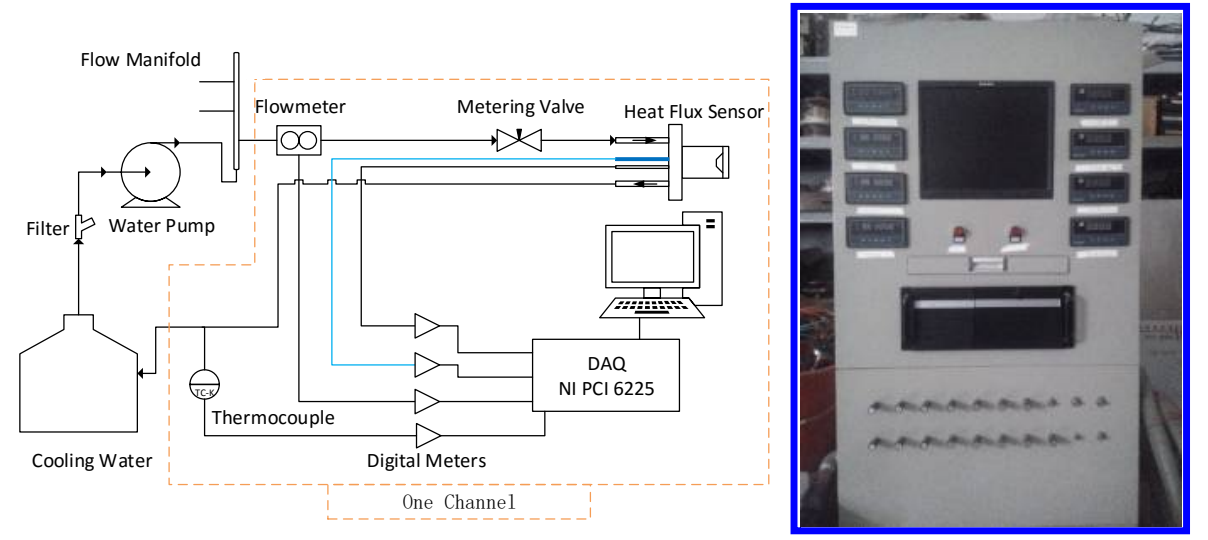

Figure 4 Heat flux measurement system (left: flow path diagram; right: photo).

In the cooling water subsystem, water was pumped by a rotary centrifugal pump (WILO MVI4101/16/E/3-380-50-2) to 10 bar and distributed by a manifold to each heat flux sensor via metering valve (XiongChuang SS-33S6F), and the flow rate was monitored by flowmeter (NU.ER.T-1.6mm-G1/4).

The heat flux sensor used in this study was developed based on the principal of Gardon gauge and improved by Cheng [14], as shown in Figure 5. The sensor's diameter is $18 \mathrm{~mm}$, which is $12 \%$ of the width of the model combustor. The surface roughness at the sensor header is polished to $\mathrm{Ra}=3.2$, the same as the inner wall of the combustor assembly. The total heat flux into the sensor is proportional to the output voltage signal, and the surface temperature at the sensor head can be estimated using the heat flux via calibrated constants.
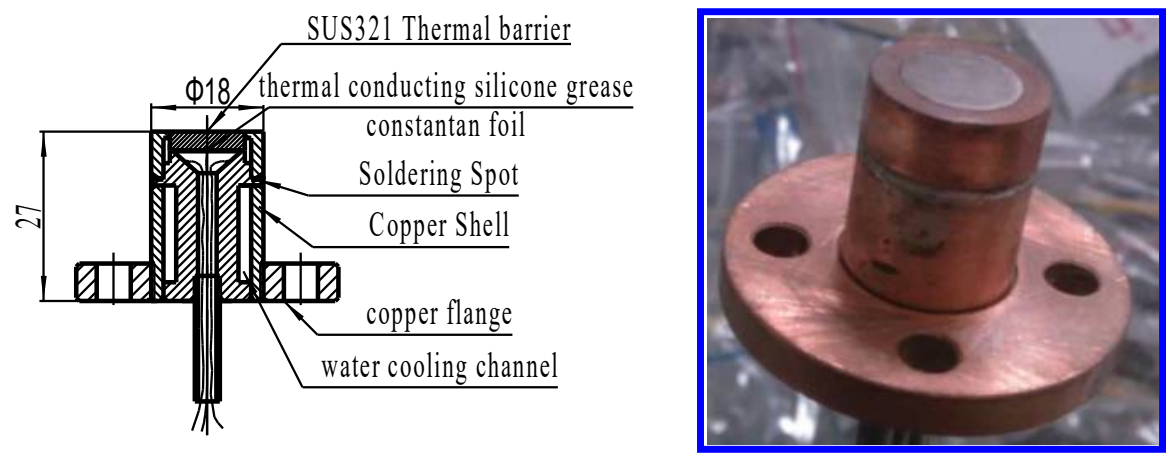

Figure 5 Left: Schematic heat flux sensor, unit: mm; Right: photo.

The heat flux sensor signals were conditioned using digital meter (Contronix CH6) and acquired by data acquisition card (NI PCI 6225) at a sampling rate of $10 \mathrm{~Hz}$ per channel. A LabVIEW program was developed to collect the experiment data. The working cooling-water flow rate is set at $30 \mathrm{~mL} / \mathrm{s}$ to ensure sufficient cooling of the heat flux sensors.

\subsection{Heat Flux Sensor Calibration}

Before each test, the heat flux sensors were calibrated via two methods: High Temperature Black Body Radiation Method (HTBBRM) and Electrical Heating Method (EHM). For EHM, as sketched in Figure 6, because the heat flux sensor and heating element is insulted by mullite bricks whose thermal conductivity is two order of magnitude lower than metals, nearly all the electric heating power is transferred through heat flux sensor and produces the signal $\mathrm{E}$ and temperature difference $\mathrm{T}_{\mathrm{h}}-\mathrm{T}_{\mathrm{b}}$. The sensitivities of the sensor can be obtained by linear fitting based on the definitions: 


$$
\begin{aligned}
& K_{1}=\frac{4 P}{\pi D^{2} E} \\
& K_{2}=\frac{T_{h}-T_{b}}{E}
\end{aligned}
$$

where $\mathrm{K}_{1}$ and $\mathrm{K}_{2}$ are heat flux and temperature difference sensitivities respectively. $\mathrm{P}$ is the heating power of the electrical heater. $\mathrm{D}$ is the diameter of the sensor head, $\mathrm{E}$ is the output signal, $\mathrm{T}_{\mathrm{h}}$ and $\mathrm{T}_{\mathrm{b}}$ are the temperatures measured at the heater surface and the sensor copper body respectively. For HTBBRM, the heat flux is generated by the blackbody radiation from a graphite cavity and monitored by an optical pyrometer, which is a standard method [14].

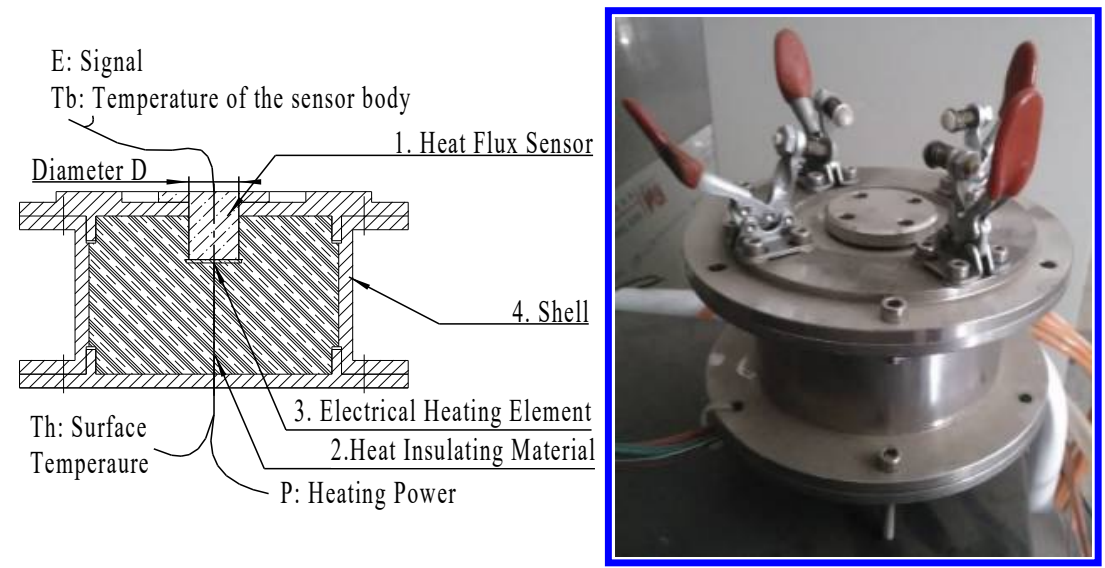

Figure 6 Schematic (Left) and photo (Right) of the Electrical Heating Method Calibration Device

The drawback of the HTBBRM is that the surface temperature of heat flux sensor is immeasurable when calibrating the heat flux sensitivity $\mathrm{K}_{1}$, and the time and cost is much higher than EHM. But a high heat flux up to $100 \mathrm{~W} / \mathrm{cm}^{2}$ can be reached. EHM can be used to calibrate the heat flux sensitivity $\mathrm{K}_{1}$ and temperature difference sensitivity $K_{2}$ simultaneously. The results show that $K_{1}$ from the two methods are within $8 \%$ difference. However, the $\mathrm{K}_{2}$ cannot be verified by other means now, so the surface temperature estimated in the test cases was given in the supplementary data and not used in the following analysis.
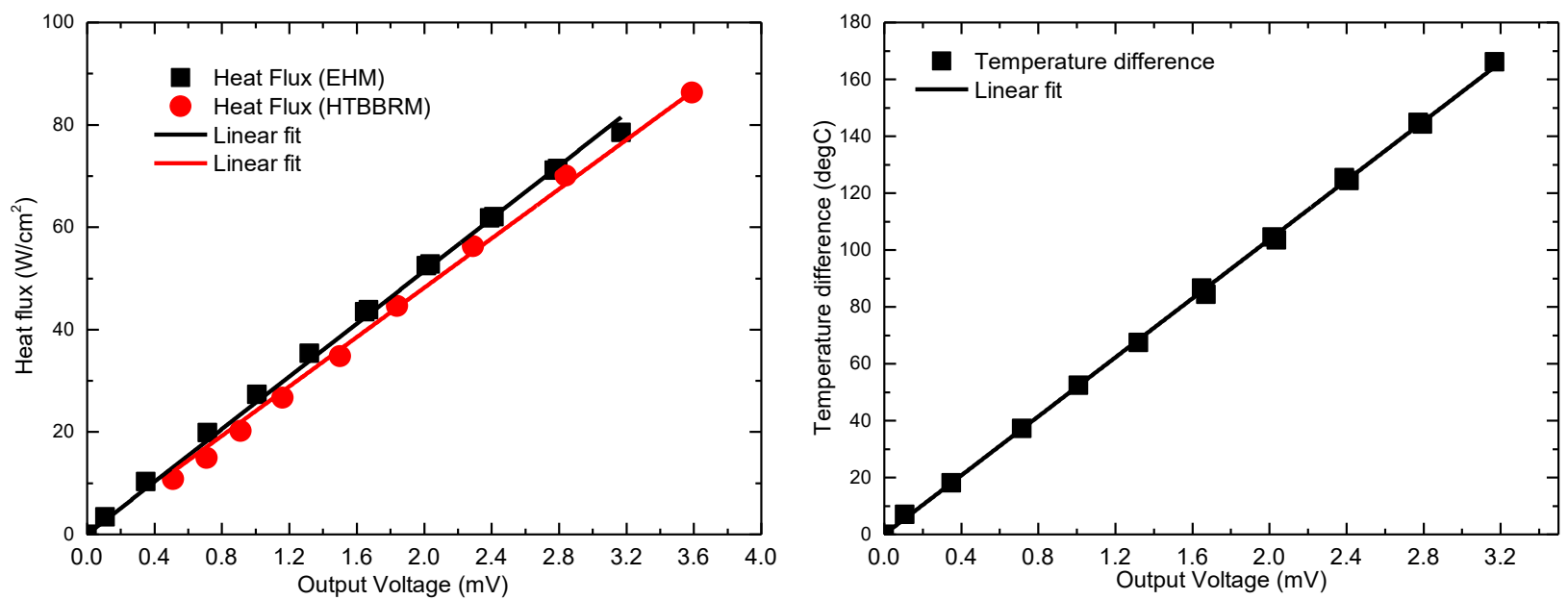

Figure 7 Calibration data of a heat flux sensor using different methods.

\subsection{Accuracy of installation and machining}

Installation errors have certain impact on the measurement accuracy and thus need to be mentioned before interpretation. There are two kind of error identified in experiment setup up like Figure 8 . The flanges 
between the three sections are matched within $1 \mathrm{~mm}$, while the isolator inlet is not so perfectly matched with the nozzle outlet but with a dimension error of around $2 \mathrm{~mm}$, accordingly the static pressure and heat flux at the first location is disturbed to be asymmetrical. The heads of heat flux sensors are aligned parallel to the inner wall surface of the test sections and with a gap distance within $0.1 \mathrm{~mm}$.

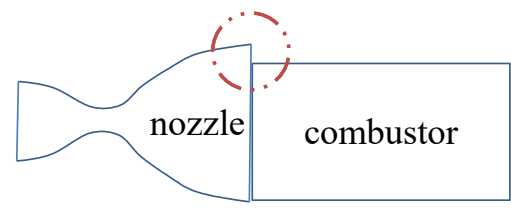

(a) Flange mismatch

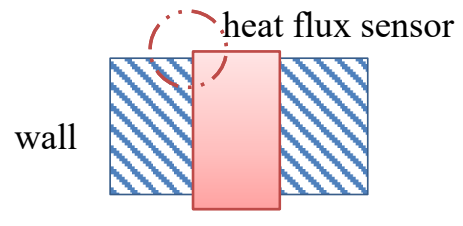

(b) sensor head misalignment

Figure 8 Schematics of installation and machining error

\subsection{Experiment procedure}

The time sequence is set as Figure 9. Data acquisition systems start $10 \mathrm{~s}$ before the test and shutdown at $10 \mathrm{~s}$ after the test. The vitiated air heater is turned on at $3 \mathrm{~s}$ and turned off at $35 \mathrm{~s}$, while the pilot $\mathrm{H}_{2}$ is activated from $18 \mathrm{~s}$ to $35 \mathrm{~s}$, and the kerosene injection is activated from $20 \mathrm{~s}$ to $35 \mathrm{~s}$. Both the aerodynamic heating and combustion heating time is set to $15 \mathrm{~s}$ respectively.

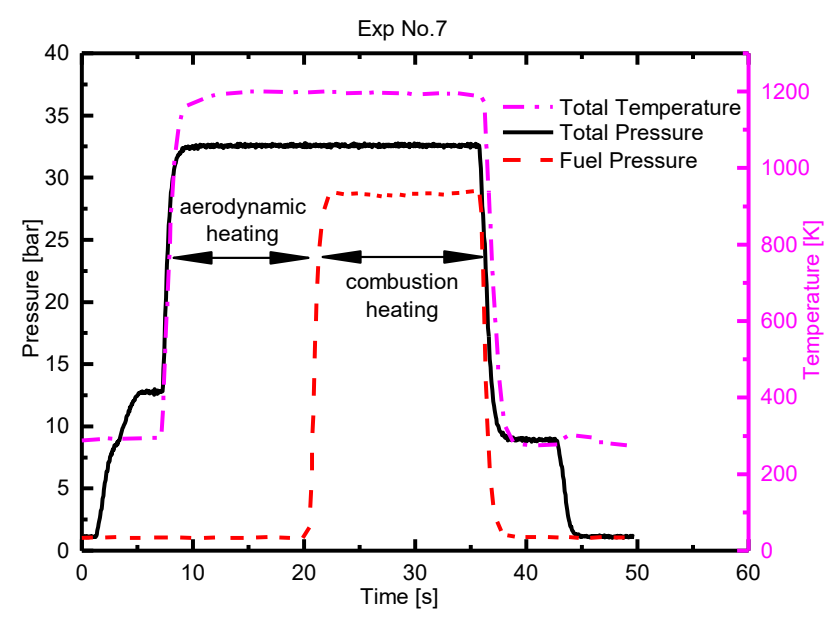

Figure 9 Pressure and temperature profile of Exp No.7

\subsection{Data processing}

The raw data consist of three parts, i.e. test facility operational parameters, streamwise static pressure, and heat flux sensor output signals. Test facility operational parameters listed in Table 1 contain the mass flow rate $q_{m}$, total temperature $T_{0}$, total pressure $P_{0}$ (which is not independent of $q_{m}$ and $T_{0}$ ), pilot hydrogen equivalence ratio $\phi_{\mathrm{H} 2}$, kerosene equivalence ratio $\phi_{k e r o s e n e}$ and nozzle design Mach number $M a$. The static pressure data was averaged over the last $50 \%$ time of each steady stage, where broken sensor data have been eliminated. The output signal of the heat flux sensor was averaged over the last 4 seconds at each stage and converted to heat flux and wall temperature using calibration data. The heat flux data measured by broken sensors were eliminated. Mach number was estimated using a quasi-1D flow analysis program based on the static pressure distribution [12]. 

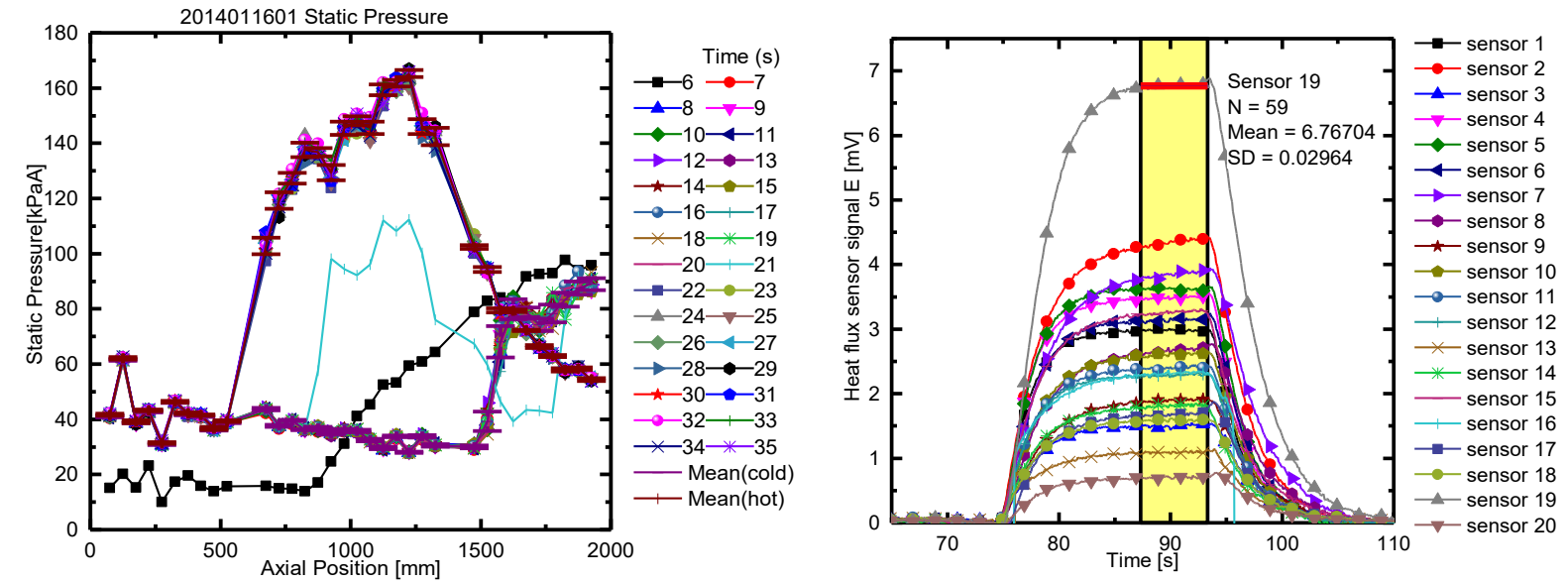

Figure 10 static pressure averaging and heat flux sensor data reduction examples.

\subsection{Test cases and grouping}

Fourteen tests were listed in Table 1. They are divided into five groups in order to study the effect of each individual factor in each group. However, part of the tests cannot be compared with corresponding control cases because there are two parameters change simultaneously.

Table 1 Test case parameters

\begin{tabular}{ccccccccc}
\hline Test & Dataset ID & Ma & $T_{0}(\mathrm{~K})$ & $p_{0}(\mathrm{bar})$ & $q_{m}(\mathrm{~g} / \mathrm{s})$ & $\phi_{\text {kerosene }}$ & $\phi_{H 2}$ & Comments \\
No. & & & & & & & & \\
\hline 1 & 2014011401 & 2.5 & 1605 & 9.66 & 3086 & 0 & 0 & Sensor test \\
2 & 2014011402 & 2.5 & 1608 & 9.6 & 3075 & 0 & 0 & Sensor test \\
3 & 2014011601 & 2.5 & 1595 & 9.53 & 3074 & 0.56 & 0.189 & Liquid fuel \\
4 & 2014012702 & 2.5 & 1619 & 9.51 & 3091 & 0.55 & 0.149 & Liquid fuel \\
5 & 2014022501 & 2.5 & 1622 & 8 & 2578 & 0 & 0 & Sensor test \\
6 & 2014031101 & 2.5 & 1627 & 8.01 & 2568 & 0.72 & 0.095 & Supercritical fuel \\
7 & 2014031701 & 2.5 & 1701 & 8.11 & 2580 & 0.59 & 0 & Supercritical fuel \\
8 & 2014031802 & 2 & 1289 & 4.16 & 2574 & 0.69 & 0.094 & Supercritical fuel \\
9 & 2014032001 & 2 & 1308 & 4.15 & 2579 & 0.88 & 0.098 & Supercritical fuel \\
10 & 2014032002 & 2 & 1308 & 4.15 & 2577 & 0.52 & 0.095 & Supercritical fuel \\
11 & 2014032103 & 2 & 1314 & 3.76 & 2008 & 0.71 & 0.096 & Supercritical fuel \\
12 & 2014032105 & 2 & 1306 & 4.94 & 3061 & 0.7 & 0.091 & Supercritical fuel \\
13 & 2014032402 & 2 & 1469 & 4.45 & 2556 & 0.7 & 0.093 & Supercritical fuel \\
14 & 2014032502 & 2 & 1686 & 4.75 & 2539 & 0.7 & 0.093 & Supercritical fuel \\
\hline
\end{tabular}

Table 2 Grouping of the test cases

\begin{tabular}{llll}
\hline Group No. & Test No. & Variable Parameter & Comments \\
\hline $\mathbf{0}$ & 1,2 & - & Sensor and facility test \\
$\mathbf{1}$ & 6,14 & $M a$ & 2.5 to 2.0 \\
$\mathbf{2}$ & $11,8,12$ & $q_{m}$ & About $2.0,2.5,3.0 \mathrm{~kg} / \mathrm{s}$ respectively \\
$\mathbf{3}$ & $10,8,9$ & $\phi_{\text {kerosene }}$ & About $0.5,0.7,0.9$ respectively \\
$\mathbf{4}$ & $8,13,14$ & $T_{0}$ & About $1300,1500,1700 \mathrm{~K}$ respectively \\
\hline
\end{tabular}




\section{Results and discussions}

\subsection{Heat flux sensor in situ test}

The first two test cases are used to check the response time and the reliability of the sensors. Both cases are conducted at the same experimental condition except that 5 pairs of heat flux sensors were exchanged and reinstalled.

Figure 11 shows the static pressure and heat flux measurements before and after swapping heat flux sensors. Pressure rise indicated by the last four sensors show the influence of back pressure induced separation. Due to the single-sided expansion of the combustor assembly, the influence of flow separation on heat flux is different for each wall. The heat flux increases from the unexpanded wall to the expanded wall, and the highest heat flux is 3.7 to 4.7 times as large as the lowest heat flux.

Figure 12 shows the response time of heat flux sensors indicated by the time period of signal rise from $5 \%$ to $95 \%$. According to those tests, the response time of the heat flux sensors installed in the combustor is $8.23 \pm 1.20 \mathrm{~s}$, accordingly the test time at every stage is set to $15 \mathrm{~s}$ to ensure that the signal $E$ has reached the plateau.

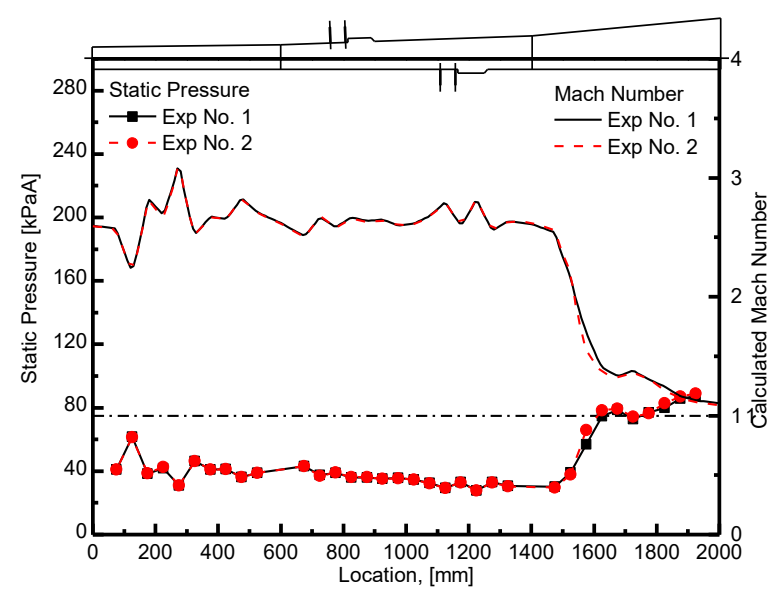

a

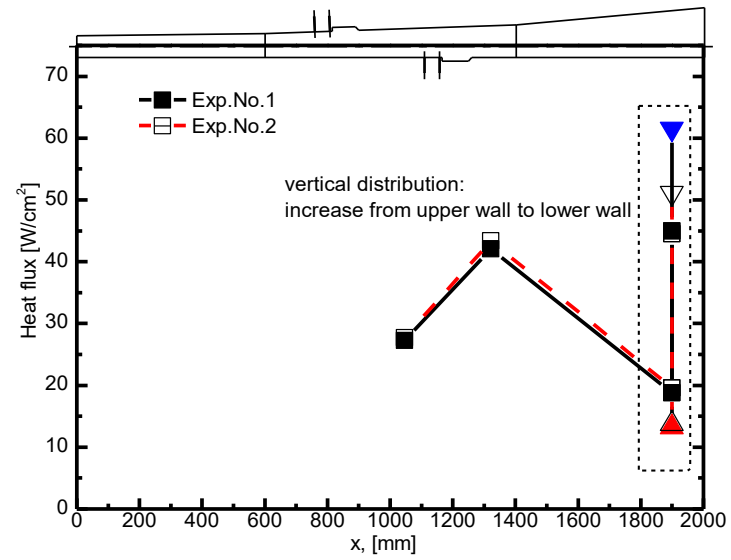

c

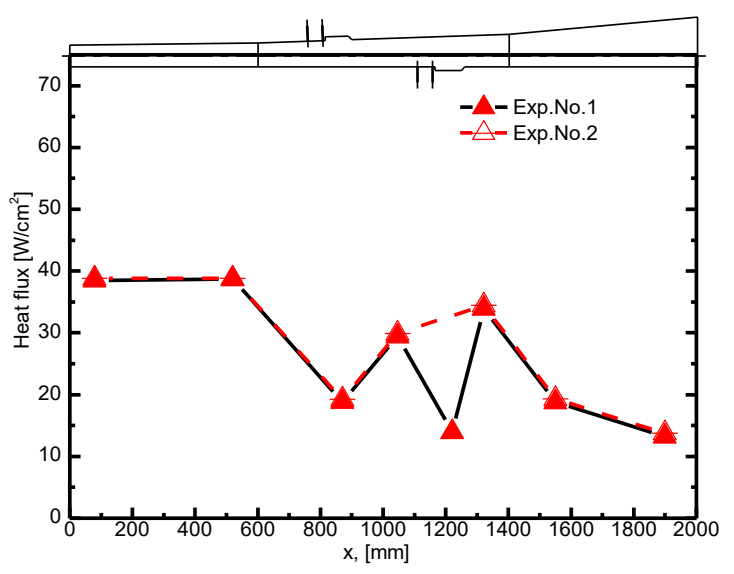

$\mathrm{b}$

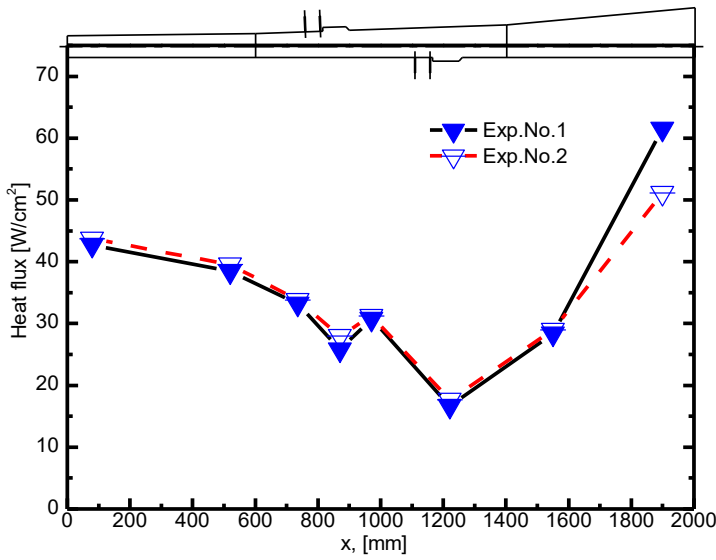

d

Figure 11 Test group 1, static pressure and heat flux measurements before and after

swapping heat flux sensors. (a) The static pressure and calculated Mach number along the horizontal line of the east wall. $(b, c, d)$ The heat flux measured on the upper, west and lower walls respectively. 


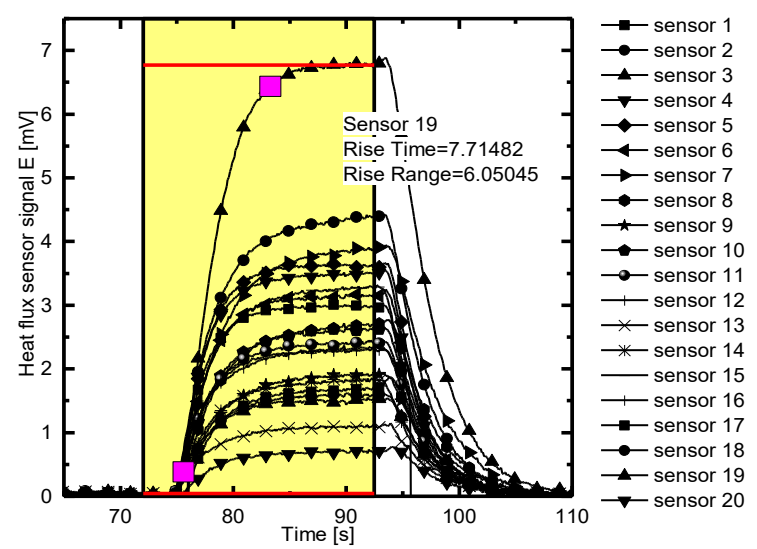

Figure $125 \%-95 \%$ rise time of a heat flux sensor during test obtained using Origin ${ }^{\circledR}$.

\subsection{Influence of combustion}

Figure 13 shows the rises in static pressure and heat flux due to the combustion. The peak static pressure is about 6 times as high as that without combustion, and the peak heat flux is about 5 times as high as that without combustion. Calculated Mach number indicates that the combustor is working at ramjet mode. The peak of static pressure lies in front of the peak of heat flux. As expected, the heat flux distribution is asymmetrical in the combustor with two dislocated cavities. The upper or lower wall heat flux rises almost immediately after the supercritical fuel injection locations. Different heat flux at the same stream wise distance is observed for each wall. This phenomena shows that the flow is highly stratified. It is because the cross flow jet penetration depth is less than 10 times of injection hole diameter which is $\varnothing 1 \mathrm{~mm}$ in the tests but the height of combustor is larger than $70 \mathrm{~mm}$ [15], and the high speed flow in the combustor left little time for sufficient mixing.

The back pressure induced flow separation is suppressed in the test with combustion, as also reflected in the vertical distribution of heat flux data points at $1900 \mathrm{~mm}$ in Figure 13 (c), where the vertical heat flux distribution is flipped, and the $\mathrm{max} / \mathrm{min}$ heat flux ratio decreases from 2.5 to 1.2 with combustion.

Another phenomena worth noticing is that the heat flux drops more rapidly on upper wall at $1400 \mathrm{~mm}$ to $1500 \mathrm{~mm}$ than that of lower wall. It can be attribute to the small turning angle of expander section with respect to combustor section. 


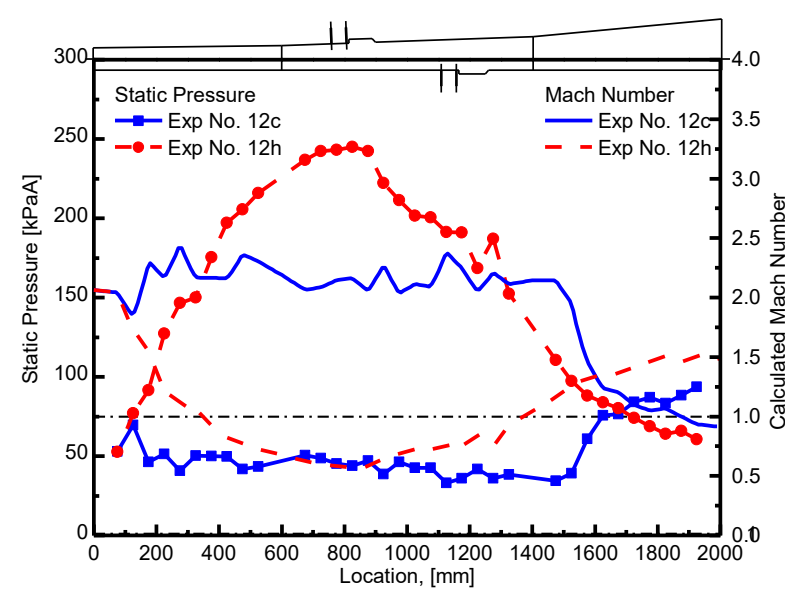

a

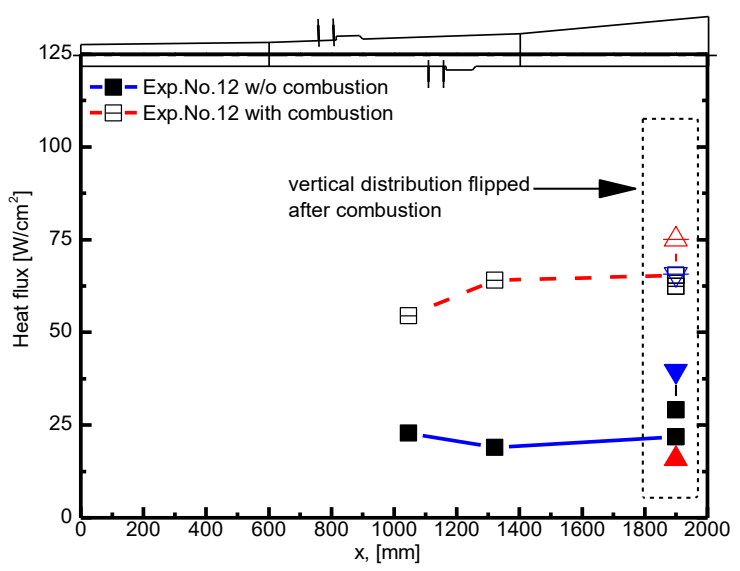

c

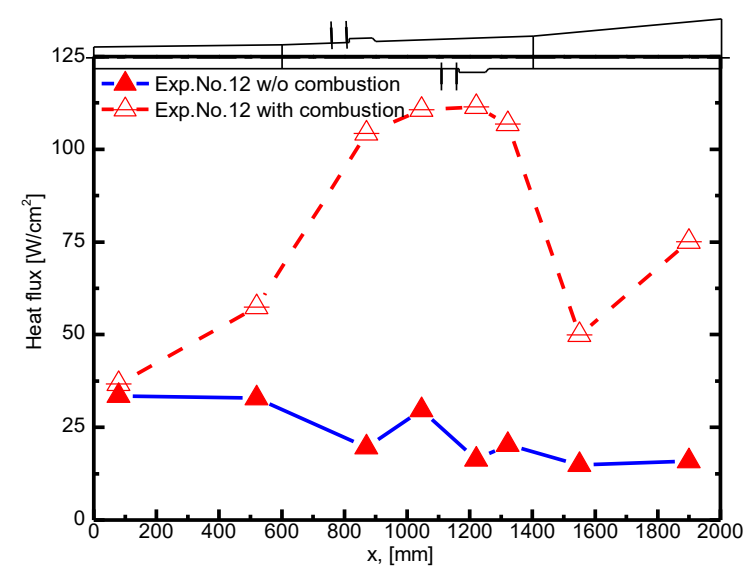

$\mathrm{b}$

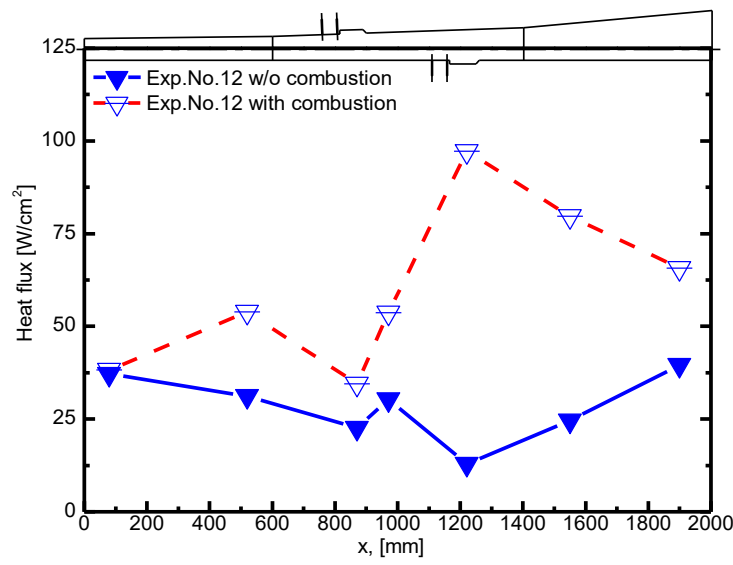

d

Figure 13 Result of Test No.12 with or without combustion. (a) The static pressure and calculated Mach number along the horizontal line of the east wall. (b,c,d) The heat flux measured on the upper, west and lower walls respectively.

\subsection{Influence of equivalence ratio}

In the test group 3, the supercritical kerosene equivalence ratio $\phi_{\text {kerosene }}$ is increased from 0.52 to 0.88 . The test data is shown in Figure 14. According to Figure 14, the combustion induced pressure rise in the

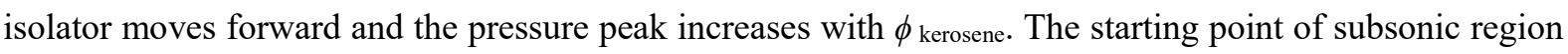
moves forward but the ending point keeps fixed as $\phi_{\text {kerosene }}$ increases. 


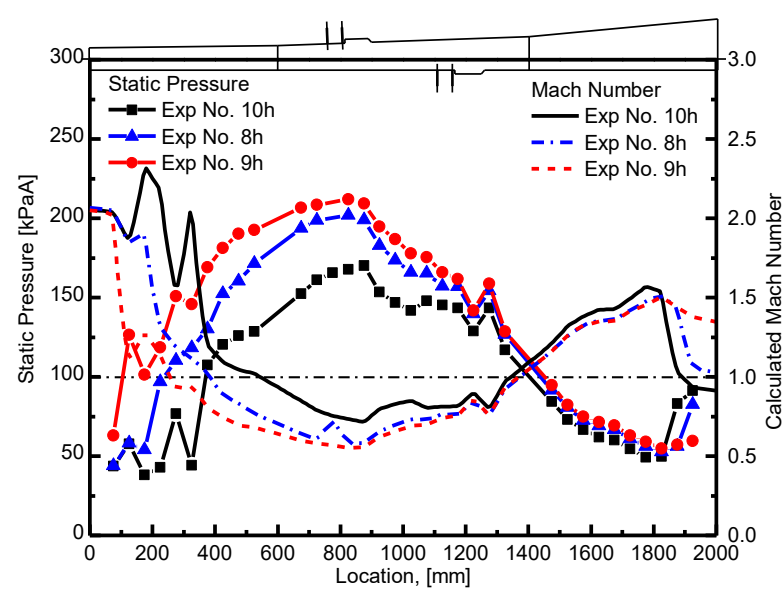

a

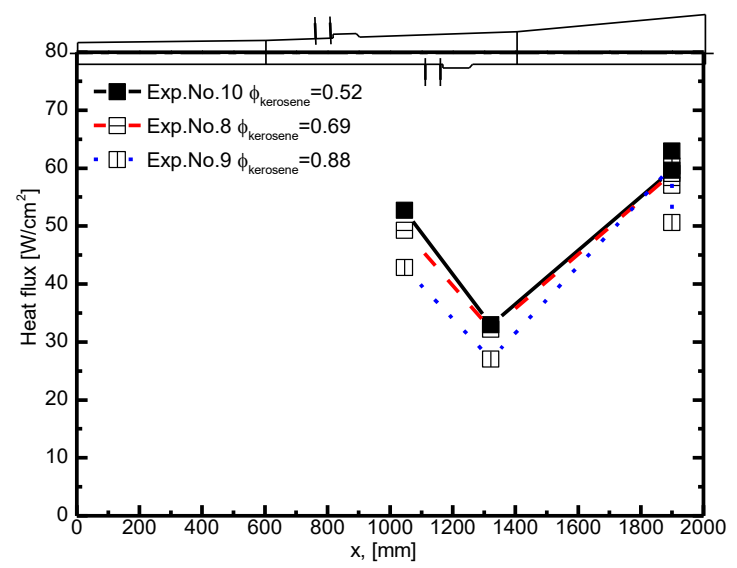

$\mathrm{c}$

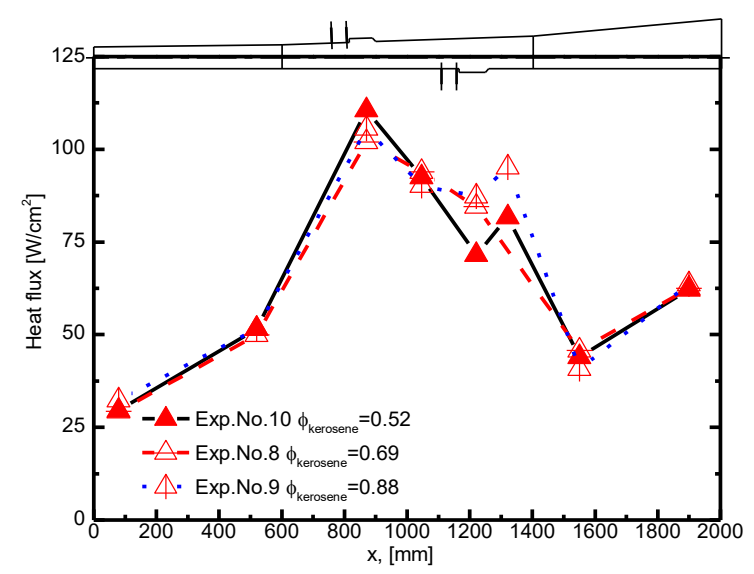

$\mathrm{b}$

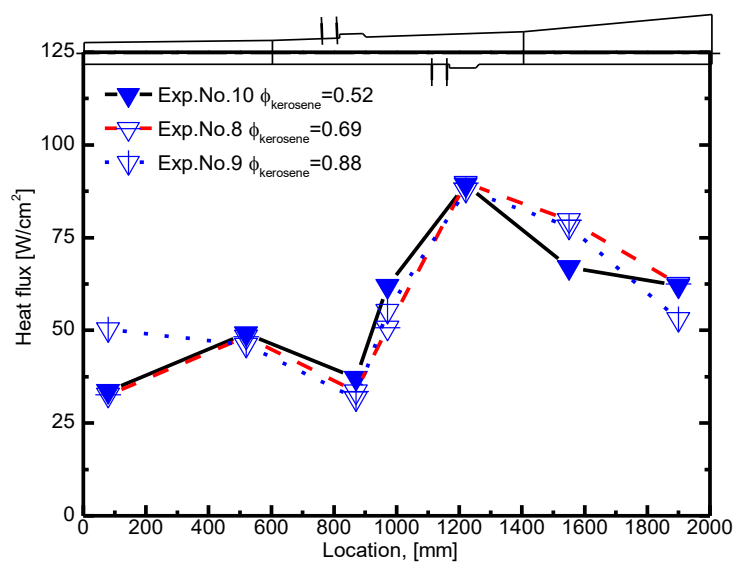

$\mathrm{d}$

Figure 14 Test group 3: $\phi_{\text {kerosene }} \approx 0.5,0.7,0.9$, keeping $T_{0} \approx 1300 \mathrm{~K}, \mathrm{q}_{\mathrm{m}} \approx 2.5 \mathrm{~kg} / \mathrm{s}, \phi_{\mathrm{H} 2} \approx 0.1$.

The heat flux varies weakly and non-monotonously with $\phi$ kerosene in the examined equivalence ratio range. This phenomena is contradictory to the previous studies.

First, we checked the cooling water outlet temperature rise in Figure 15. The cooling water flow rate for combustor section is kept at $2.23 \pm 0.01 \mathrm{~kg} / \mathrm{s}$ for all tests. The curve of cooling water outlet temperature indicates that the total heating rate is almost the same and even decrease with equivalence ratio.

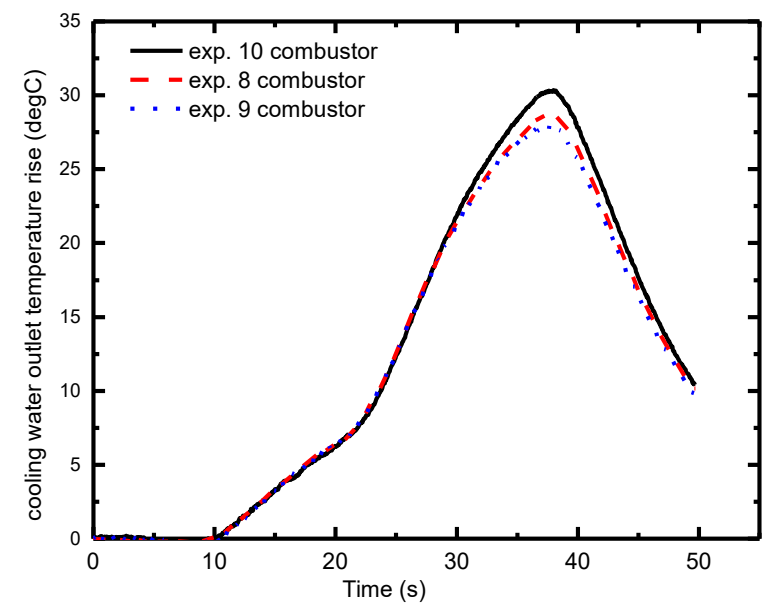

Figure 15 cooling water temperature rise history during experiment. 
A possible explanation is the variation in the injection pressure of the supercritical kerosene. In the tests, the supercritical kerosene is always choked to control its mass flow rate and avoid downstream interference, thus the mass flow rate is determined solely by the stagnation pressure. In order to reduce the $\phi_{\text {kerosene, }}$, the upstream pressure of supercritical kerosene is decreased from 49 bar, 37.9 bar to 28.7 bar for Test No.9, 8 and 10 correspondingly, where the penetration depth reduces accordingly. And we suppose the nearer to the wall the combustion zone is, the more heat release is transferred to the wall. The rapidly decreasing pressure profile in the second half of the combustor also indicates the combustion is insufficient for higher injection pressure. However, further study of this phenomenon is needed to verify this explanation.

Another interesting phenomena is the first heat flux measurement of lower wall in Exp.No.9. It is the only abnormal heat flux rise in all test cases. This heat flux rise can be attributed to the combustion induced pressure rise which has propagated upward to isolator inlet. It is an evidence of shock wave induced heat flux rise in the isolator.

\subsection{Influence of mass flow rate}

The results of test group 2 are shown in Figure 16. According to Figure 16, the general trends of static pressure, calculated Mach number and heat flux distribution are similar for the test cases at different mass flow rates, but the magnitudes of them increase almost monotonously with increasing mass flow rate except at the separation zone occurred at the exit. The peak of heat flux varies nearly proportionally with the mass flow rate because according to theoretical analysis, the heat flux $\dot{q}$ is proportional to $q_{m}{ }^{0.8}$ :

$$
q=\text { St } \rho u c_{p} \Delta T \approx \frac{0.0287}{\operatorname{Pr}^{2 / 5} \operatorname{Re}^{1 / 5}} \times \frac{q_{m}}{A} \times c_{p} \Delta T \propto q_{m}^{0.8}
$$




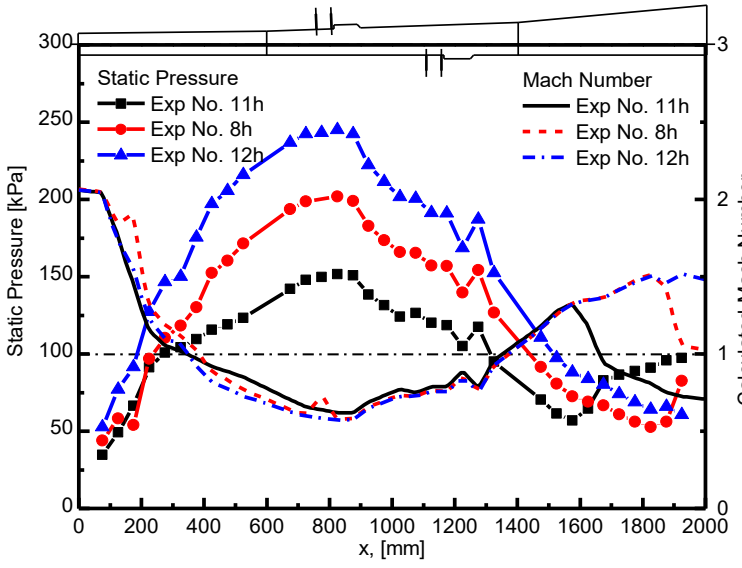

a

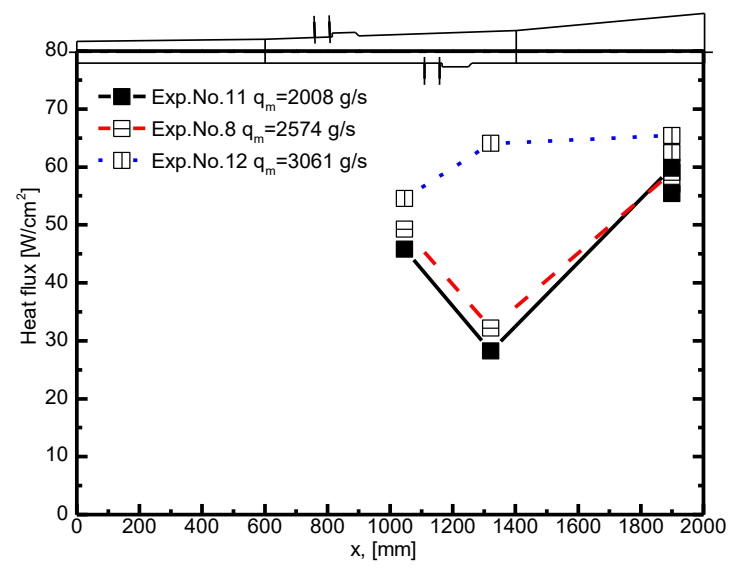

c

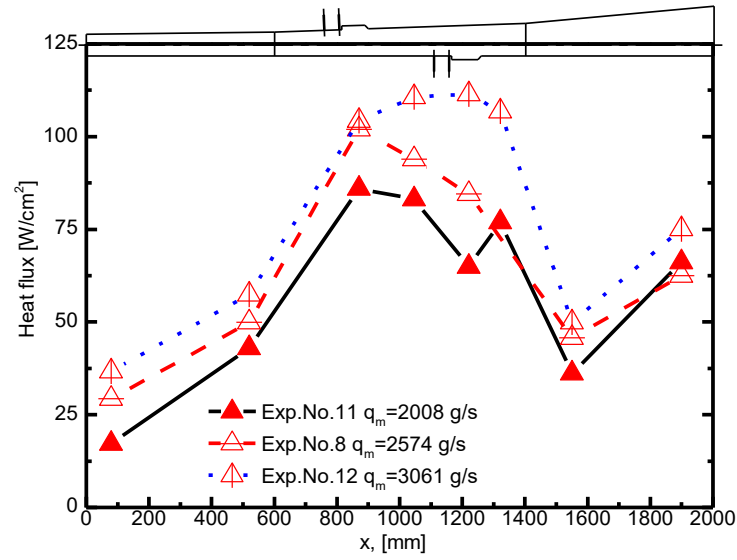

b

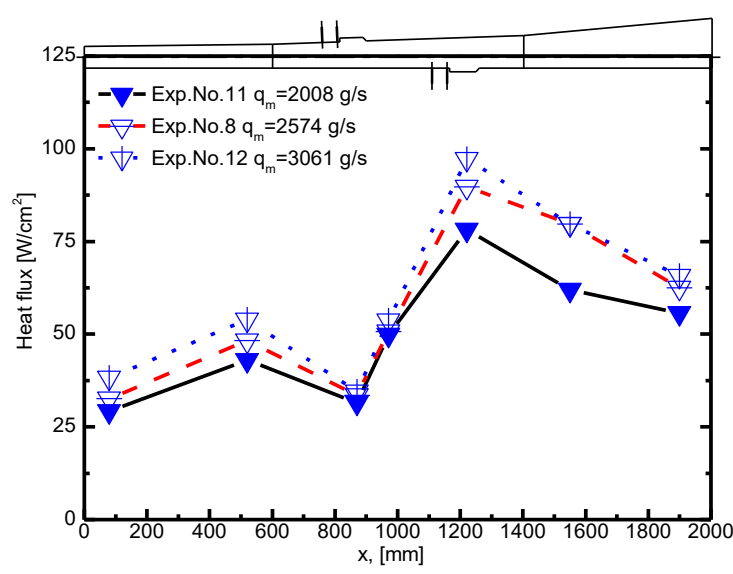

$\mathrm{d}$

Figure 16 Test group 2: $q_{\mathrm{m}}$ changes from $2.0 \mathrm{~kg} / \mathrm{s}$ to $3.0 \mathrm{~kg} / \mathrm{s}$, keeping $\mathrm{T}_{0} \approx 1300 \mathrm{~K}, \phi_{\mathrm{kerosene}} \approx 0.7$, $\phi_{\mathrm{H} 2} \approx 0.1$.

\subsection{Influence of total temperature}

The test results of group 4 are shown in Figure 17. According to Figure 17, increasing $T_{0}$ moves pressure rise location in the isolator forward and increases the peak static pressure, and the length of subsonic region is shortened. But the static pressure distributions after the first cavity are almost the same. The heat flux increases with $T_{0}$, and the general trend is almost the same for lower wall. But for the upper wall, the shape becomes different in high heat flux region after the first cavity. The trend indicates that the upper wall heat flux decrease more rapidly for lower $T_{0}$ case. 


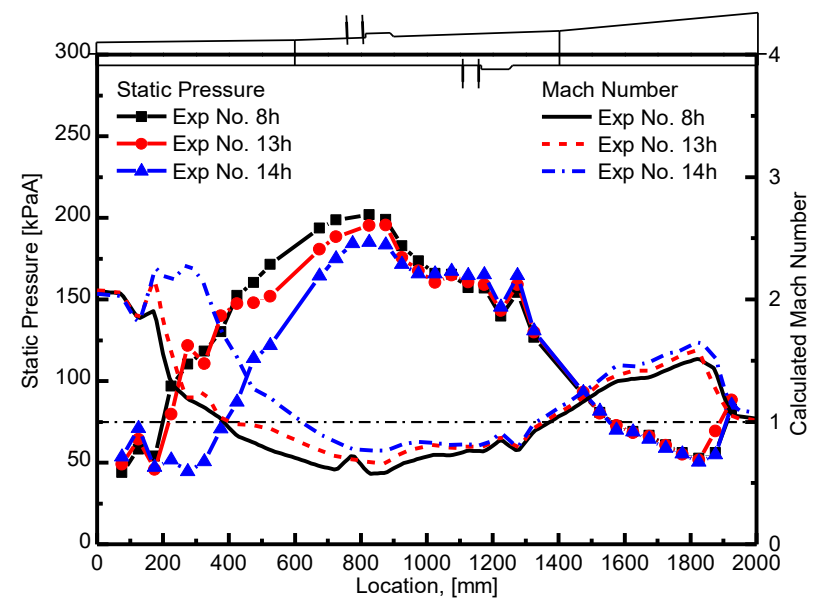

a

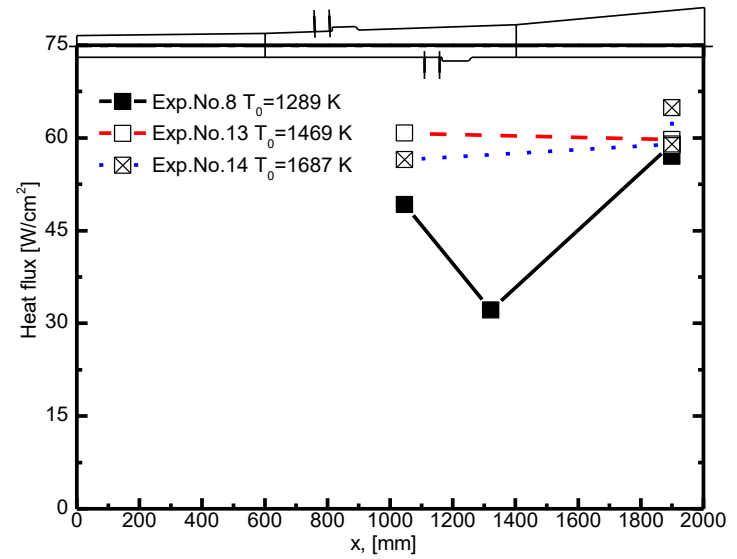

c

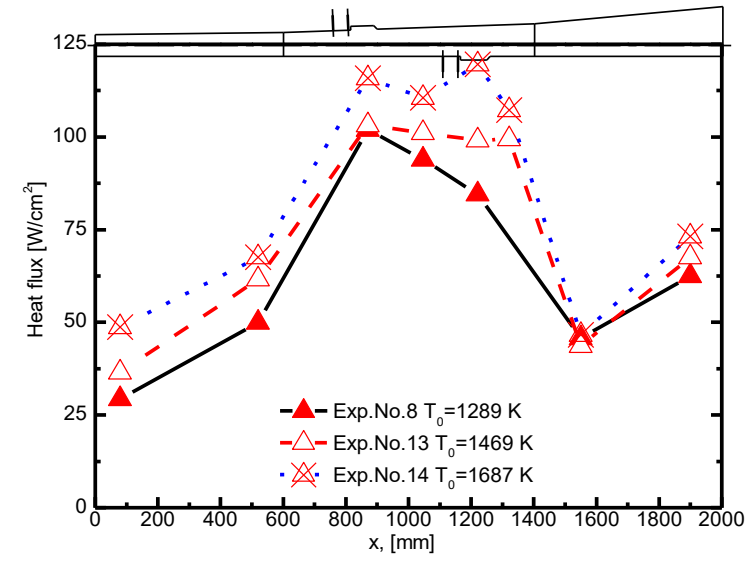

$\mathrm{b}$

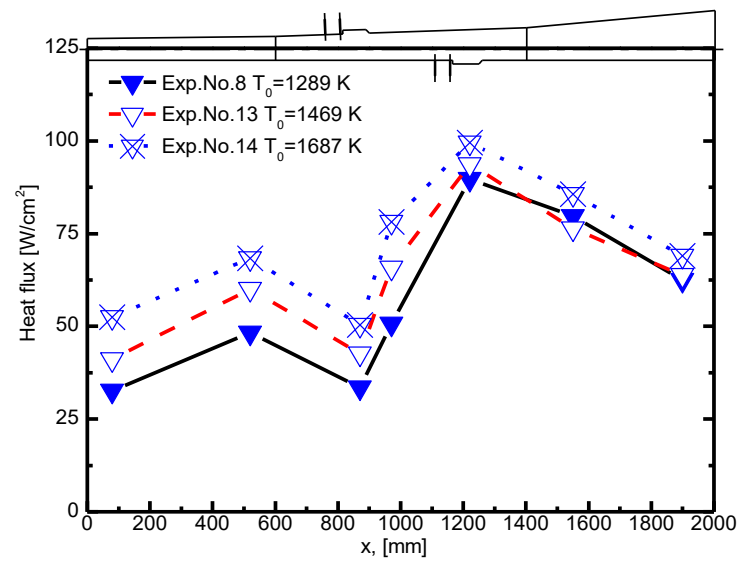

d

Figure 17 Test group 4 with $T_{0}$ varies from $1289 \mathrm{~K}$ to $1687 \mathrm{~K}$, keeping $\mathrm{q}_{\mathrm{m}} \approx 2.5 \mathrm{~kg} / \mathrm{s}$,

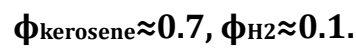

\subsection{Influence of inlet Mach number}

The test results of group 4 are shown in Figure 18. According to Figure 18, the Mach 2.5 inlet flow shows lower static pressure and a farther initial pressure rise location. But in the expansion section, the pressure distributions are almost the same for the two examined inlet Mach numbers. According to the calculated Mach number, the combustor works at scramjet mode in the Mach 2.5 case and ramjet mode in Mach 2.0 case.

The heat flux distributions show more complicated behavior than the static pressure distributions, since the influence of combustion mode cannot be easily evaluated. Because the total temperature is the same, higher Mach number result in higher Reynolds number and hence lower Stanton number. The recovery temperature is also lower for higher Mach cases. As a result, the isolator heat flux of Mach 2.5 case is lower than Mach 2.0 cases. On the upper wall, the heat flux of Mach 2.5 case is lower than that of Mach 2.0 case until the last sensor location. But on the lower wall, the heat flux of Mach 2.5 flow becomes higher after the isolator. This phenomenon shows that both heat flux magnitude and asymetricity has been greatly influenced by the inlet Mach number. 


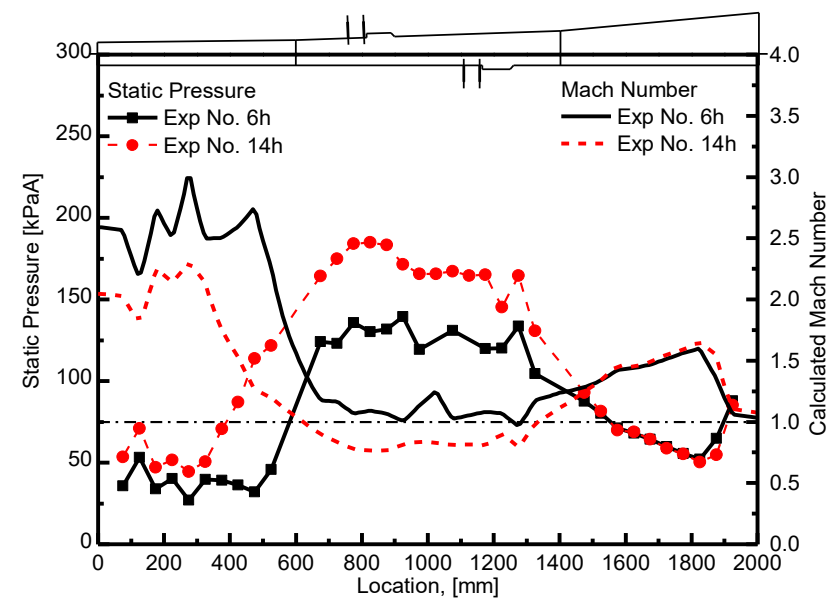

a

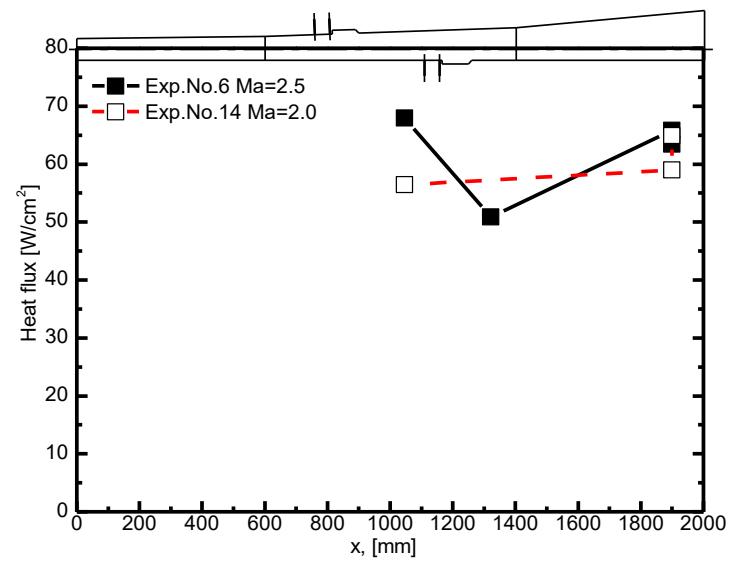

c

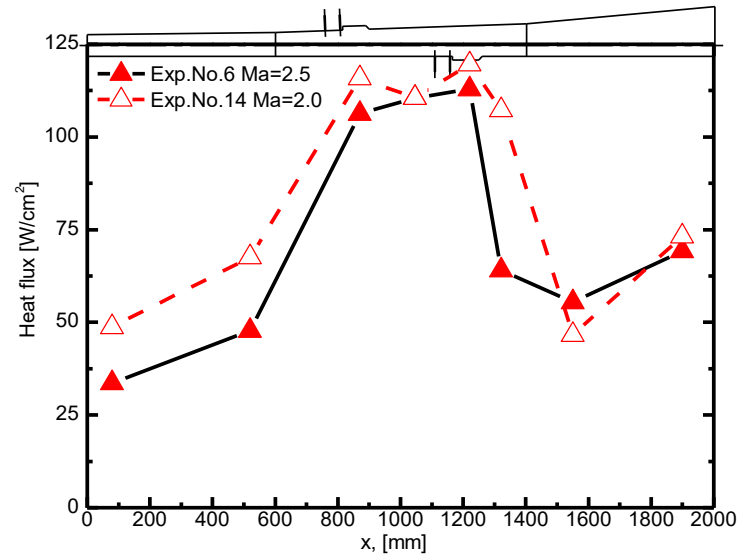

$\mathrm{b}$

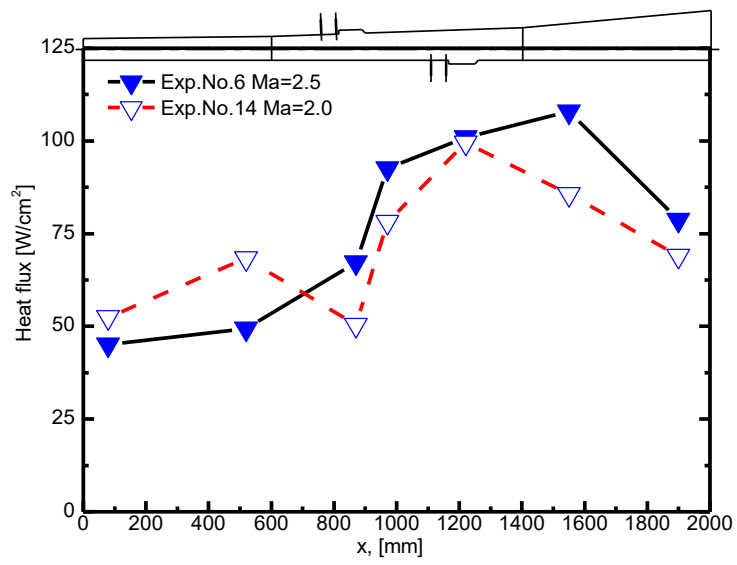

d

Figure 18 Test group 1 with test cases of inlet Mach 2.5 and Mach 2.0, keeping $\mathrm{T}_{0} \approx 1650 \mathrm{~K}, \mathrm{q}_{\mathrm{m}} \approx$ $2.5 \mathrm{~kg} / \mathrm{s}, \phi_{\text {kerosene }} \approx 0.7, \phi$ H2 $\approx 0.1$.

\section{Analysis}

According to the existing literatures, the radiative heat flux contributes no more than $10 \%$ of the convective heat flux in scramjet combustor of limited size [16, 17]. So the radiative heat transfer is neglected in the following analysis. And the heat flux can be calculated by the equation (3).

$$
q=h \times\left(T_{a w}-T_{w}\right)+q_{r a d} \approx h \times\left(T_{a w}-T_{w}\right)
$$

where $h$ is the convective heat transfer coefficient of the gas, $T_{w}$ and $T_{a w}$ are the inner wall and adiabatic wall temperatures. According to the widely used $T_{a w}$ correlation[1], and because the $\operatorname{Pr}^{*} \approx 0.73$ and $\gamma \approx 1.30$ in the range of interest,

$$
T_{a w}=T+\sqrt[3]{\operatorname{Pr}^{*}} \frac{u^{2}}{2 c_{p}}=T_{0} \times \frac{1+\sqrt[3]{\operatorname{Pr}^{*}} \frac{\gamma}{\gamma-1} M a^{2}}{1+\frac{\gamma}{\gamma-1} M a^{2}} \approx(0.93 \pm 0.01) T_{0} \text { for Ma } \in[1,4]
$$

the $T_{a w}$ is primarily determined by $T_{0}$ and is almost independent of Mach number in range 1 to 4 , Thus, it arrives,

$$
q \approx h\left(0.93 \mathrm{~T}_{0}-\mathrm{T}_{w}\right)
$$


With sufficient cooling water flow and thermal resistant coating, wall temperature $T_{w}$ varies little. So the variation of heat flux can be attributed to two major factors, i.e. the change of $h$ and the change of $T_{0}$ :

$$
\frac{\delta q}{q} \approx \frac{\delta h}{h}+\frac{0.93 \times \delta T_{0}}{0.93 T_{0}-T_{w}}
$$

In the supersonic combustor with given inflow total temperature $T_{0}$, the heat loss to the wall is usually negligible. The only cause of large variation of $T_{0}$ is the combustion. Comparing the results with and without combustion, and the results of group 4 , it can be clearly seen that the total temperature impacts heat flux significantly.

On the other hand, $h$ depends on the local condition of boundary layer. For turbulent flat plate boundary layer, there is correlation to determine $h$ as equation (7).

$$
h=\mathrm{St}_{\rho u c_{p}} \approx \frac{0.0287}{\operatorname{Pr}^{2 / 5} \mathrm{Re}_{x}^{1 / 5}} \times \frac{q_{m}}{A} c_{p} \approx \frac{0.0287 c_{p} \mu^{0.2}}{\operatorname{Pr}^{2 / 5}} \times q_{m}^{0.8} A^{-0.8} x^{-0.2}
$$

If the boundary layer grows without disturbance, $h$ decreases with $x^{-0.2}$ for turbulence boundary layer on flat surface without pressure gradient. But the flow field in supersonic combustor is filled with disturbances such as shockwave, flow separation, combustion, fuel injection and geometric sharp turns. The boundary layer may be thickened or even separated by adverse pressure gradient, which changes heat transfer. even small local separation can cause large rise in peak heat flux at a factor of 2-3 [1]. The heat flux rise at the exit of combustor caused by pressure induced flow separations is an evidence of the influence of adverse pressure gradient. Another evidence is the coincidence of the heat flux rise and pressure rise in the isolator where $T_{0}$ does not increase yet.

However, the combustion and boundary layer are closely coupled in the supersonic combustor. The contributions of $T_{0}$ and $h$ are difficult to separate. The heat flux distribution is non-monotonously affected by various flow parameters, and a through parameter analysis of the heat flux distributions need to be combined with the internal flow field analysis in the combustor to interpret the results.

\subsection{Three-parameter correlation of average heat flux in the isolator}

Considering a relatively simple flow in the isolator without combustion, the average heat flux of isolator only depends on $T_{0}, M a$ and $q_{m}$. Based on the form of equation (5) and (7), a three-parameter correlation formula is proposed,

$$
\text { i } \quad{ }^{8} \times\left(\mathrm{T}_{0}-c\right) \times\left(1+\mathrm{b} \times \mathrm{Ma}^{2}\right)
$$

where the dependence of Mach number is added to account for compressible effects.

The experimental data in the Table 3 is used for the fitting, and a resulted equation is given as equation(9).

$$
\frac{i}{\left[\mathrm{~W} / \mathrm{cm}^{2}\right]}-. .03 \times\left(\frac{q_{m}}{[\mathrm{~kg} / \mathrm{s}]}\right)^{0.8} \times\left(\frac{\mathrm{T}_{0}}{1000[\mathrm{~K}]}-0.653\right)\left(1-0.05766 \times \mathrm{Ma}^{2}\right)
$$

The fitted results are shown in Figure 19, and the correlation quality is summarized in Table 4, where the $\mathrm{R}^{2}=0.98$ means that $98 \%$ of the heat flux can be successfully explained by the semi-empirical formula (8).

Table 3 Independent, dependent and fitted data of average heat flux in the isolator

\begin{tabular}{cccccc}
\hline Exp.No. & Ma & $\mathrm{T}_{0}$ & $\mathrm{q}_{\mathrm{m}}$ & $\dot{q}_{\text {avg,isolator }}$ & fitted $\dot{q}$ \\
\hline & 18 \\
American Institute of Aeronautics and Astronautics
\end{tabular}




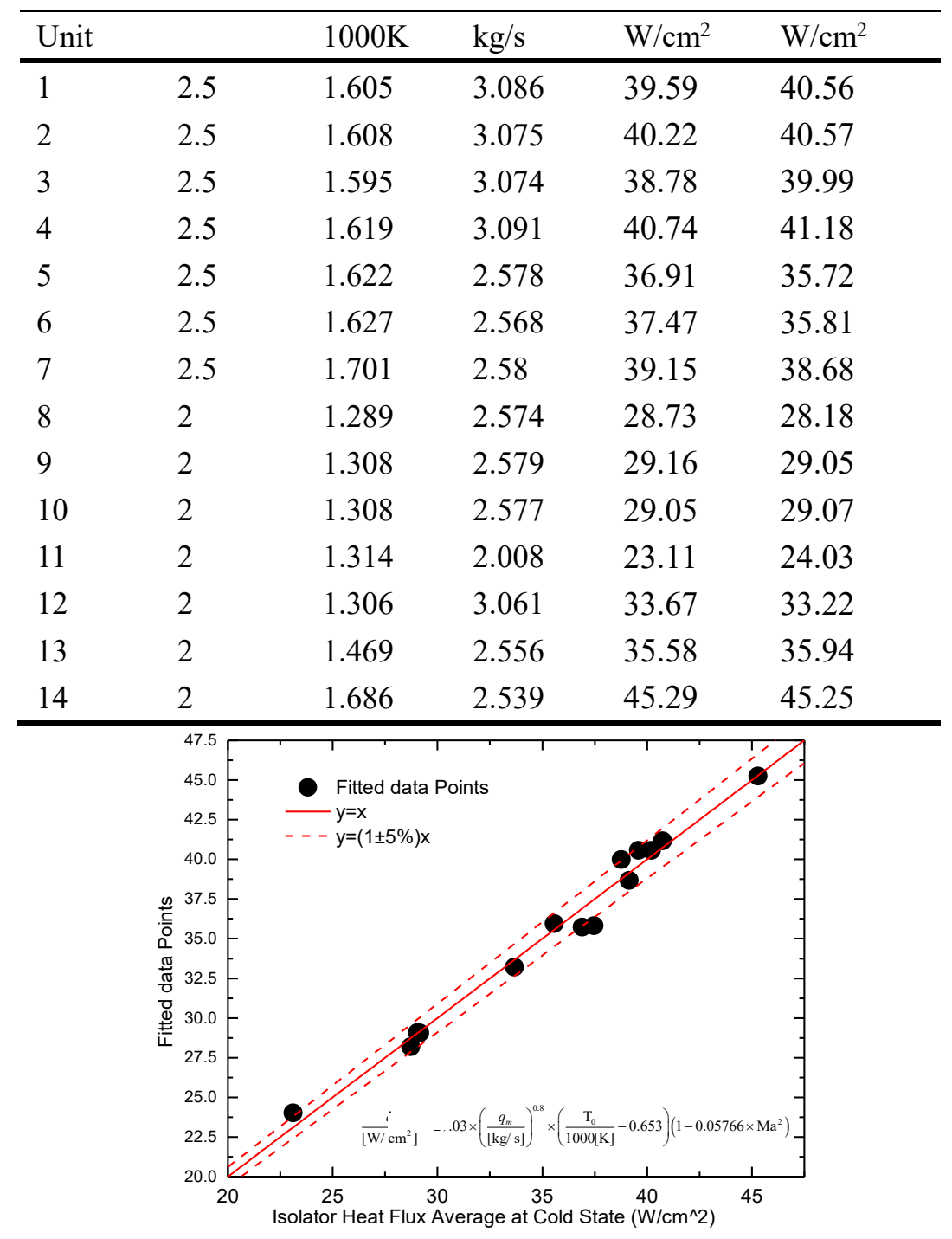

Figure 19 Fitted results

Table 4 Summary of the correlation quality

\begin{tabular}{cccccccc}
\hline \multicolumn{2}{c}{ K } & \multicolumn{2}{c}{$\mathrm{c}$} & \multicolumn{2}{c}{$\mathrm{b}$} & \multicolumn{2}{c}{ Statistics } \\
\hline \multirow{2}{*}{ Value } & $\begin{array}{c}\text { Standard } \\
\text { Error }\end{array}$ & Value & $\begin{array}{c}\text { Standard } \\
\text { Error }\end{array}$ & Value & $\begin{array}{c}\text { Standard } \\
\text { Error }\end{array}$ & $\begin{array}{c}\text { Reduced } \\
\chi^{2}\end{array}$ & Adj. R $^{2}$ \\
\hline 27.02864 & 1.94519 & 0.6529 & 0.0408 & -0.05766 & 0.00394 & 3.12408 & 0.9787 \\
\hline
\end{tabular}

Figure 20 shows the normalized heat flux using Eq. (9) for all cases. Without combustion, the agreement is good for heat flux in the front part of combustor but becomes bad in the expander section. This suggests that the cavities and expansion deteriorate the similarity of heat flux distributions. For Mach 2.0 cases, the divergence begins at the flow separation region. For Mach 2.5 cases, the divergence begins at the first cavity, which indicates the Mach 2.5 flow is more easily to be disturbed.

With combustion, for Mach 2.0 cases, the magnitude diverges after fuel injection, but the trends are almost the same. The peak normalized heat flux nearly increase with decreasing total temperature. For Mach 2.5 cases, the liquid fuel and supercritical fuel shows significant different heat flux distribution pattern. The correlation fitted with cases without combustion underestimated the influence of total temperature in combustion region. The peak location of liquid fuel cases is behind the supercritical fuel cases and the asymmetricity is more significant for liquid fuel cases. 

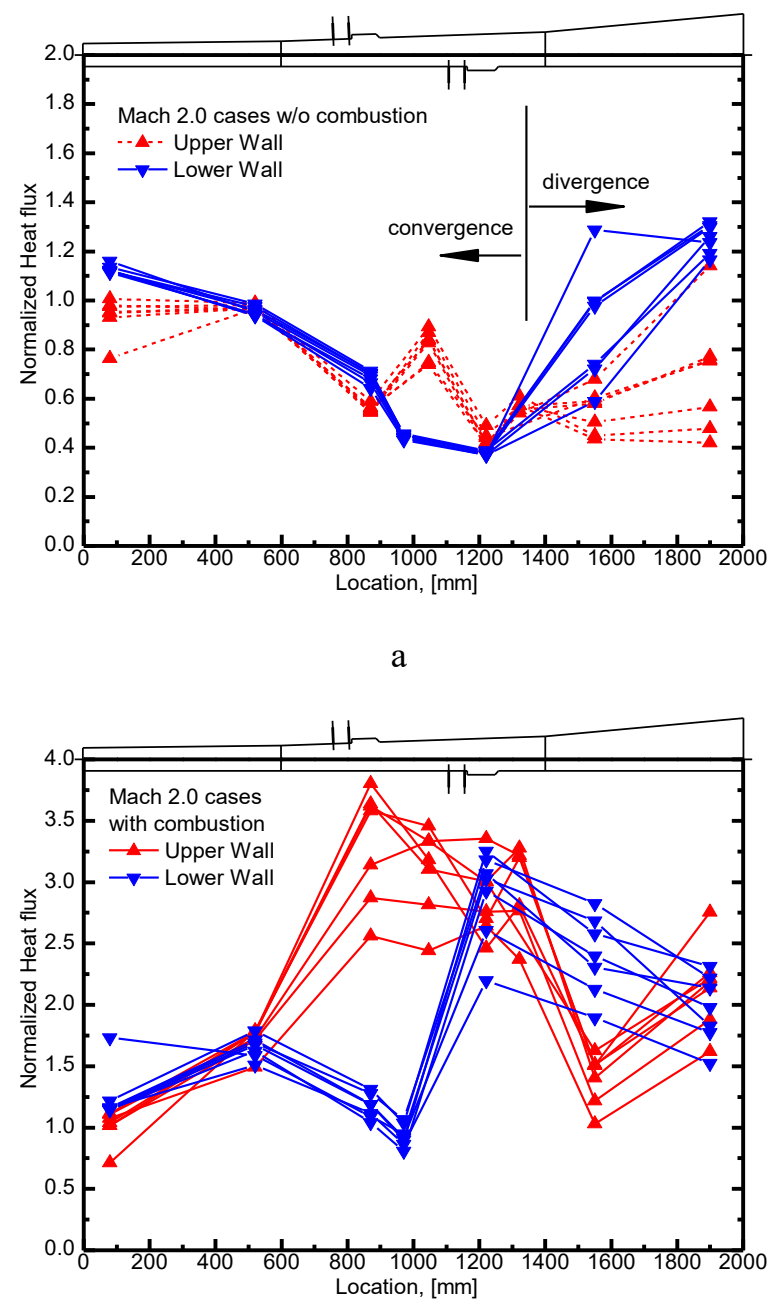

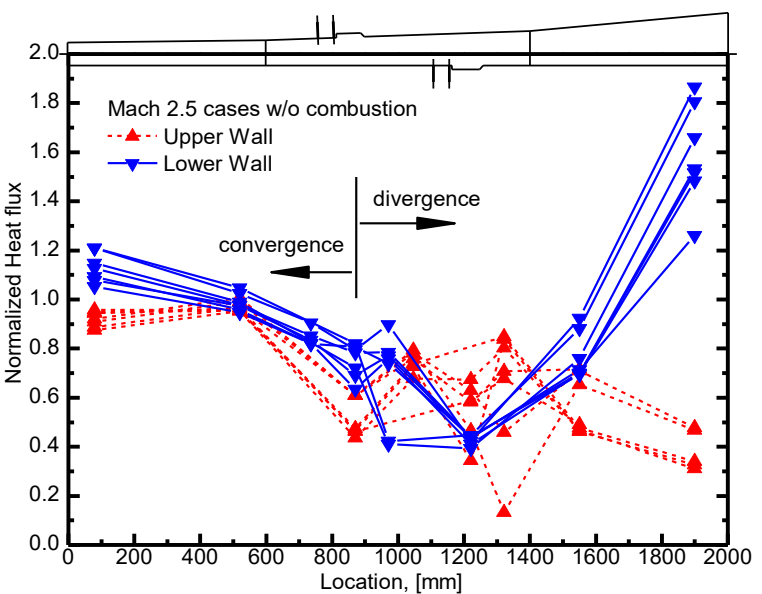

b

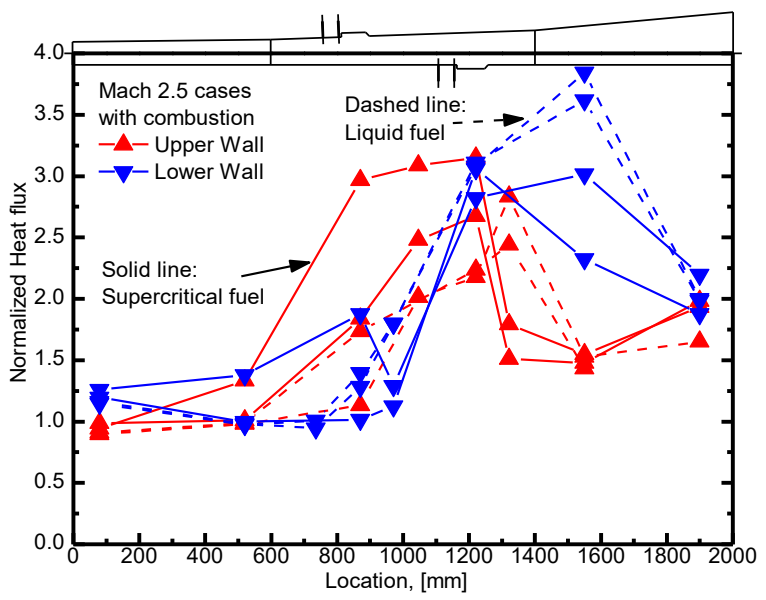

d

Figure 20 Normalized heat flux distribution

\section{Concluding remarks}

In this study, measurements of heat flux distribution of a water cooled supersonic combustor with two dislocated cavities were performed. Some important conclusions can be drawn from the analysis as follows.

- Flow in the scramjet combustor with dislocated cavities is stratified and the heat flux distribution is asymmetric. When flow separation occurred due to unmatched ambient pressure, the heat flux on unexpanded wall is higher than that on expanded wall.

- Combustion significantly influences the general trend and the magnitude of heat flux distributions. The ratio of peak heat flux after and before combustion is 2.35 to 3.40 in the investigated parameter range, and the maximum heat flux with combustion is 5.0 to 7.8 times of the local heat flux before combustion. In general trend, the heat flux of each wall rises gradually with combustion induced pressure rise and increases sharply just before the injection fuel. The peak heat flux location is not fixed but the high heat flux plateau including the peak covers about 4 to 5 times of the cavity length for each wall, then the heat flux decreases gradually in the expander section except at the exit where a small rise may occur due to the flow separation caused by unmatched ambient pressure.

- The normalized heat flux distribution is relatively insensitive to mass flow rate and inflow total temperature. But the magnitude increases with increasing mass flow rate and inflow total temperature. 
The heat flux depends on mass flow rate with an exponent of 0.8 , which conforms to turbulent boundary layer theory. The influence of equivalence ratio on the heat flux distribution is observed to be insignificant and non-monotonous, which is possibly due to that the decrease of kerosene injection pressure causes closer combustion zone to the walls. The influence of inlet Mach number is more profound and complicated because different combustion modes are involved. Further investigation the influencing mechanism of those parameters is needed.

- A three-parameter correlation as a function of total temperature, inlet Mach number and mass flow rate is proposed to fit for average heat flux in the isolator without combustion. The heat flux distribution normalized using the correlation indicates there is certain similarity in cases without combustion, which is stronger in Mach 2.0 cases than Mach 2.5 cases. But the similarity can be disturbed by combustion and cavities.

\section{Acknowledgment}

The current research program at the Chinese Academy of Sciences was supported by the National Natural Science Foundation of China under No.91016005 and No.10621202. The authors would like to acknowledge Prof. Gong Yu for his helpful discussions, Jingquan Wang for preparation of heat flux sensors, Peng Huang and Guoping Hou for their technical support.

\section{Reference}

1 Heiser, W. H., and Pratt, D. T., Hypersonic airbreathing propulsion. American Institute of Aeronautics and Astronautics, Washington, D.C., 1994.

2 Zhang, T., Wang, J., Qi, L., Fan, X., and Zhang, P., "Blowout Limits of Cavity-Stabilized Flame of Supercritical Kerosene in Supersonic Combustors," Journal of Propulsion and Power Vol. 30, No. 5, 2014, pp. 1161-1166.

3 Li, L., Fan, X., and Wang, J., "Measurements of Wall Heat Flux and Temperature in a Supersonic Model Combustors," AIAA 2011-5916, 47th AIAA/ASME/SAE/ASEE Joint Propulsion Conference \& Exhibit, San Diego, California, 31 July - 03 August, 2011.

4 Morgan, R. G., and Stalker, R. J., "Shock tunnel measurements of heat transfer in a model scramjet," Journal of Spacecraft and Rockets Vol. 23, No. 5, 1986, pp. 470-475.

5 Traci, R. M., Farr, J. L., Jr., and Tony, L., "A thermal management systems model for the NASA GTX RBCC concept," NASA, NASA/CR-2002-211587, Washington, DC, June, 2002.

$6 \quad$ Stouffer, S. D., Neumann, R. D., and Emmer, D. S., "Thermal Performance of a Scramjet Combustor Operating at Mach 5.6 Flight Conditions," WRIGHT LABORATORY, WL-TR-97-2086, WRIGHT-PATTERSON AFB, OHIO, Oct., 1997.

7 Ueda, S., Takegoshi, M., Kouchi, T., Ono, F., Saito, T., and Izumikawa, M., "Evaluation of Heat-flux on Scramjet Engine Wall in Mach 6 Flight Condition," IAC-06-C4.5.4, 57th International Astronautical Congress, Valencia, Spain, 02-06 October, 2006.

8 Kennedy, P. J., Donbar, M. J., Trelewicz, J. R., Gouldstone, C., and Longtin, J. P., "Heat Flux Measurements in a Scramjet Combustor Using Direct Write Technology," AIAA 2011-2330, 17th AIAA International Space Planes and Hypersonic Systems and Technologies Conference, San Francisco, California, 11 - 14 April, 2011.

9 Jason, T., Christopher, G., Jon, L., Jeffrey, D., and Paul, K., "Diagnostic Sensing for Scramjet Combustors," AIAA 2011-2329, 17th AIAA International Space Planes and Hypersonic Systems and Technologies Conference, San Francisco, California, 11-14 April, 2011.

10 Gardner, A. D., Hannemann, K., Steelant, J., and Paull, A., "Ground Testing of the HyShot Supersonic Combustion Flight Experiment in HEG and Comparison with Flight Data," AIAA 2004-3345, 40th 
AIAA/ASME/SAE/ASEE Joint Propulsion Conference and Exhibit, Fort Lauderdale, Florida, 11-14, July, 2004.

11 Jan Martinez, S., Sebastian, K., Klaus, H., and Johan, S., "Ground Testing of the HyShot II Scramjet Configuration in HEG," 15th AIAA International Space Planes and Hypersonic Systems and Technologies Conference, Dayton, Ohio, 28 April - 1 May, 2008.

12 Li, L., "High Temperature Heat Flux Sensor and Its Application to Thermal Environment Measurement in Scramjet Combustor (in Chinese)," Ph.D. Dissertation, Insititute of Mechanics, Graudate University of Chinese Academy of Sciences, Beijing, 2011.

13 Fan, X., Yu, G., Li, J., Zhang, X., and Sung, C. J., "Investigation of vaporized kerosene injection and combustion in a supersonic model combustor," Journal of Propulsion and Power Vol. 22, No. 1, 2006, pp. 103-110.

14 Li, L., Wang, J., and Fan, X., "Development of integrated high temperature sensor for simultaneous measurement of wall heat flux and temperature," Review of Scientific Instruments Vol. 83, No. 7, 2012, pp. 074901-074910.

15 Billig, F. S., and Schetz, J. A., "Penetration of gaseous jets injected into a supersonic stream," JOURNAL OF SPACECRAFT AND ROCKETS Vol. 3, No. 11, 1966, pp. 1658-1665.

16 Liu, J., and Brown, M., "Radiative Heating in Hydrocarbon-fueled Scramjet Engines," AIAA 2012-3775, 48th AIAA/ASME/SAE/ASEE Joint Propulsion Conference \& Exhibit, Atlanta, Georgia, 30 July - 1 August, 2012.

17 Nelson, H. F., "Radiative Heating in Scramjet Combustors," Journal of Thermophysics and Heat Transfer Vol. 11, No. 1, 1997, pp. 59-64. 